\title{
Modelagem e Simulação de um Atuador Elétrico Linear
}

\section{Modeling and simulation of a linear electric actuator}

Gabriela Cristina Paiva Martins

Autora

Mauro Speranza Neto

Orientador

Allan Nogueira de Albuquerque

Co-orientador

Rio de Janeiro, 30 de junho de 2016

Área de concentração: Mecânica Aplicada 


\section{Resumo}

Um atuador linear elétrico é um equipamento que converte o movimento de rotação de um motor de baixa voltagem de corrente contínua em um movimento linear. Neste estudo serão apresentadas simulações para compreender o comportamento do atuador Linak LA12 que será acoplado a uma plataforma plana. É proposto um procedimento de modelagem de sistemas físicos, baseado no Grafo de Ligações do sistema, para obtenção da sua resposta dinâmica e consequentemente utilização desta informação para a sua análise e projeto. Para obtenção do momento de inércia equivalente, necessário na simulação do modelo simplificado, é utilizada a ferramenta Solidworks.

\section{Palavras-chaves}

Atuador elétrico linear; Grafo de Ligação; Fluxo de potência; Simulink; Solidworks. 


\begin{abstract}
An electric linear actuator is a device that converts the rotary motion of a low voltage DC motor to a linear movement. This study presents the behavior of Linak LA12 actuator that will be coupled to a planar platform with three degrees of freedom. It is proposed a procedure for modeling physical systems based on the Bond Graphs approach to obtain its dynamic response and therefore use this information for simulation. The Solidworks tool is used to obtain the equivalent moment of inertia, necessary in the simulation of the simplified model.
\end{abstract}

\title{
Keywords
}

Linear electric actuator; Bond graph; Power flow; Simulink; Solidworks. 


\section{Sumário}

1 Introdução

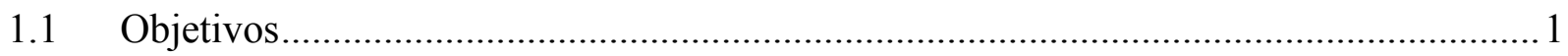

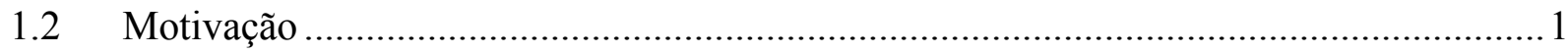

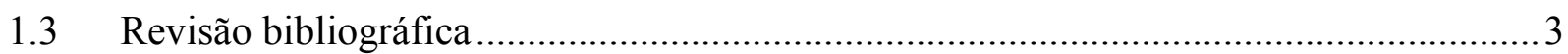

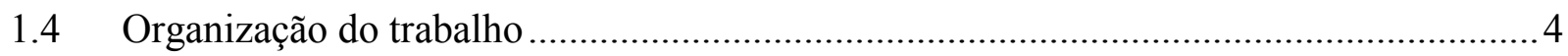

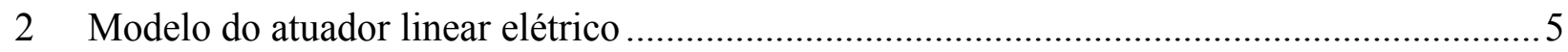

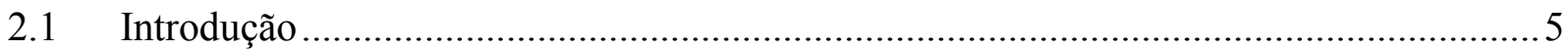

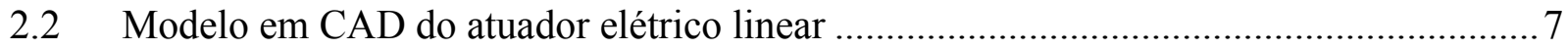

2.3 Dinâmica do atuador elétrico linear via grafos de ligação ............................................. 9

2.4 Momento de inércia equivalente do conjunto motor-engrenagem ............................. 15

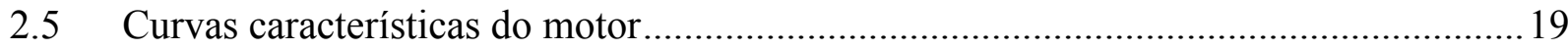

3 Simulações para avaliação dos modelos desenvolvidos .......................................................22

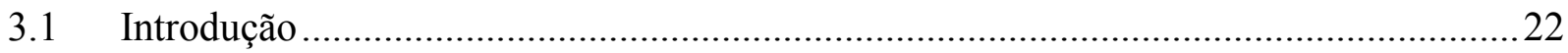

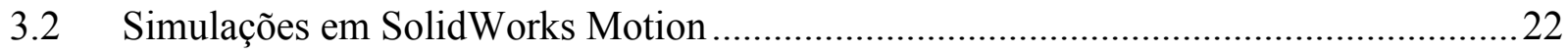

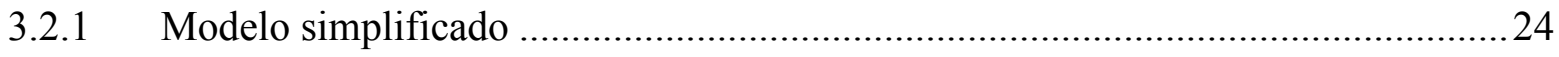

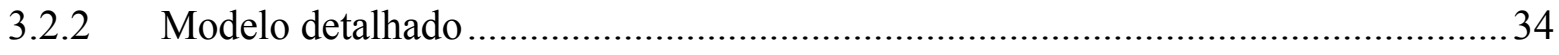

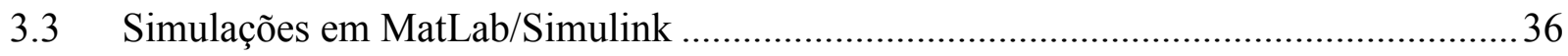

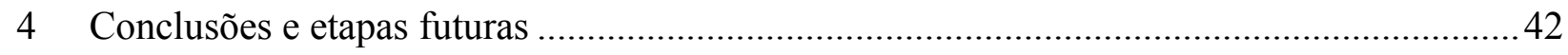

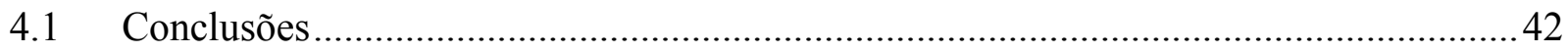

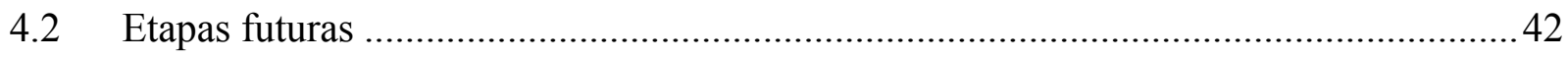




\section{Índice de figuras}

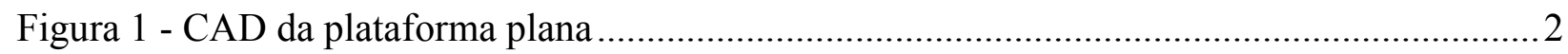

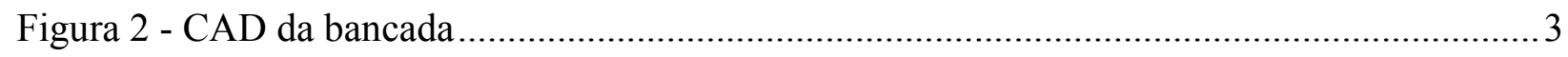

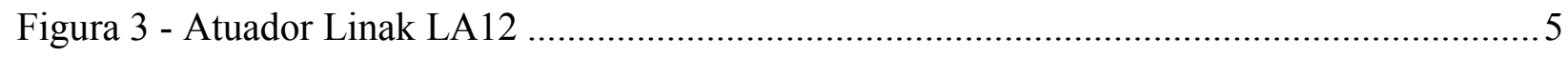

Figura 4 - Modelo esquemático do atuador..................................................................... 6

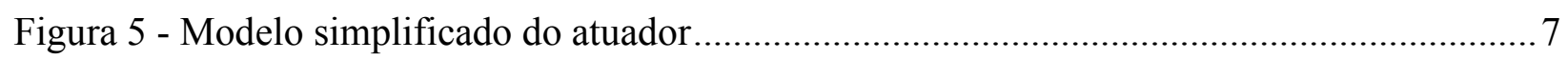

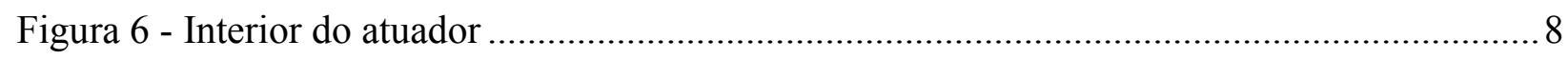

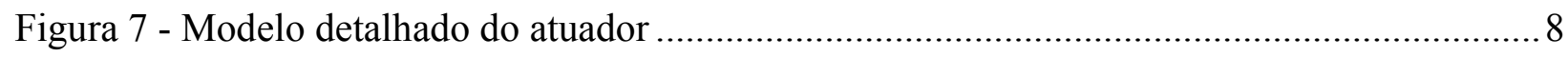

Figura 8 - Modelo do atuador detalhado (vista frontal) .................................................. 8

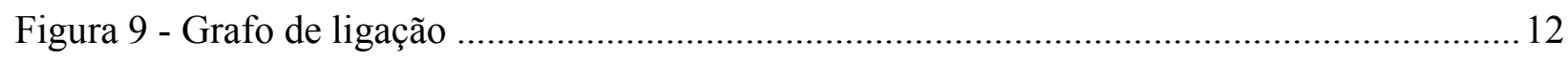

Figura 10 - Grafo de ligação com causalidade forçada ......................................................... 14

Figura 11 - Grafo de ligação simplificado ...................................................................... 14

Figura 12 - Corpo de massa M girando livremente em torno de um eixo estabelecido ................ 16

Figura 13 - Sistema de engrenagem ideal ................................................................... 17

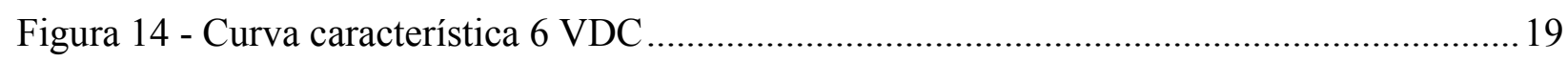

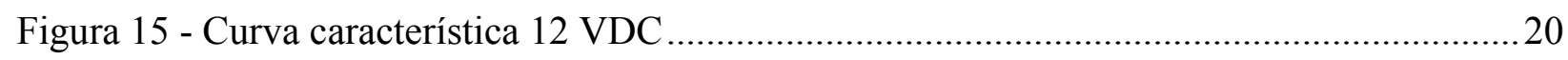

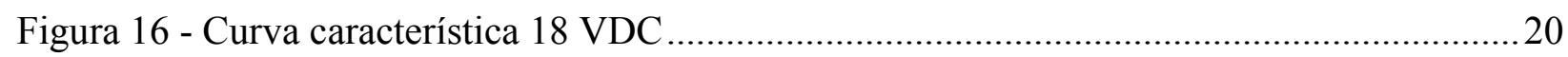

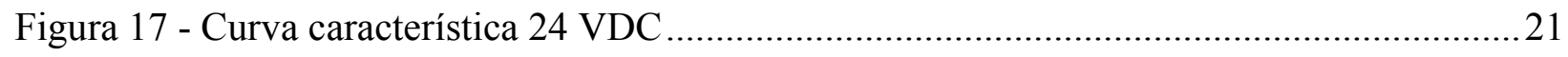

Figura 18 - Atuador com uma mola e um amortecimento linear ...........................................24

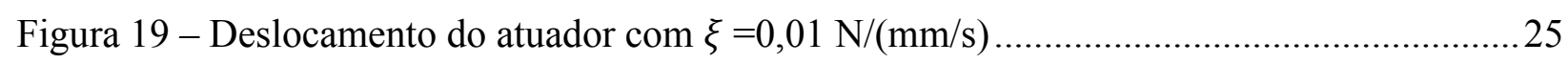

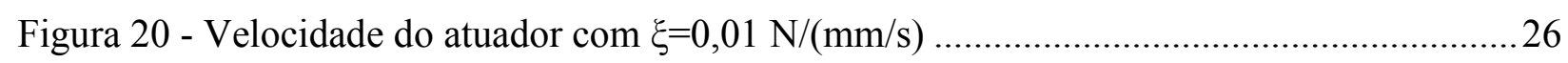

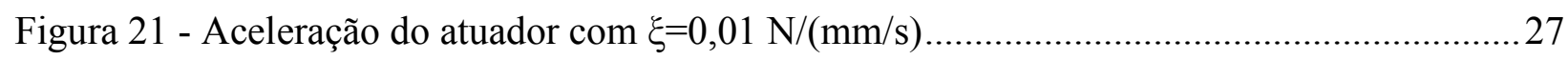

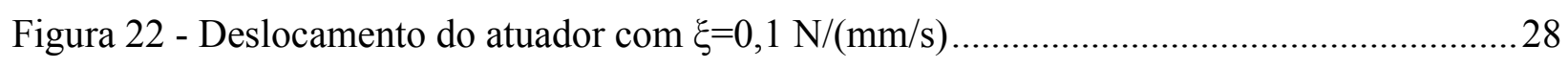


Figura 23 - Velocidade do atuador com $\xi=0,1 \mathrm{~N} /(\mathrm{mm} / \mathrm{s})$

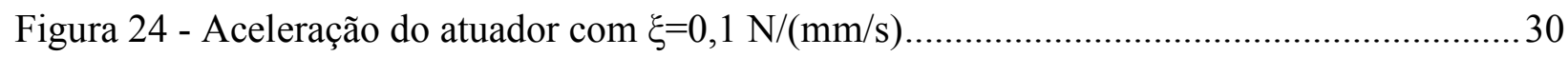

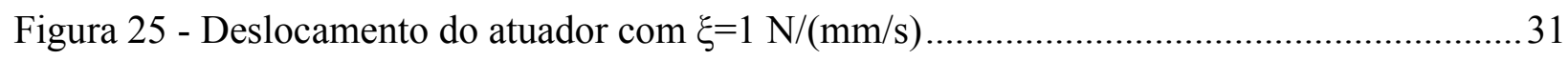

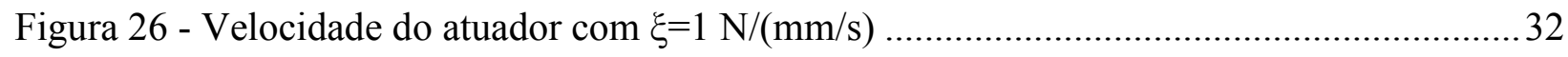

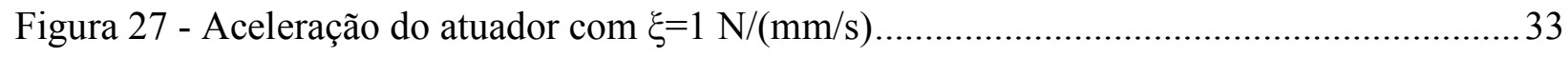

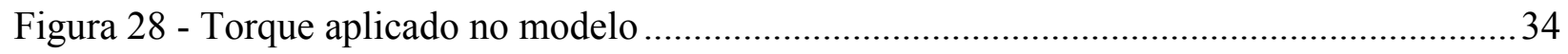

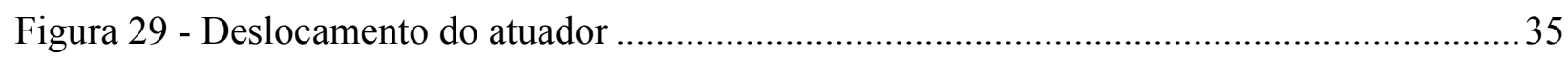

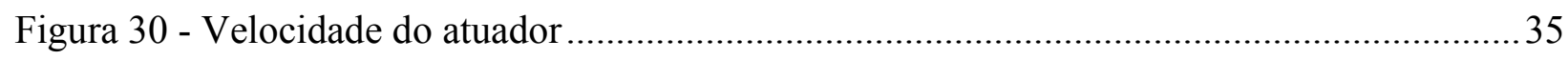

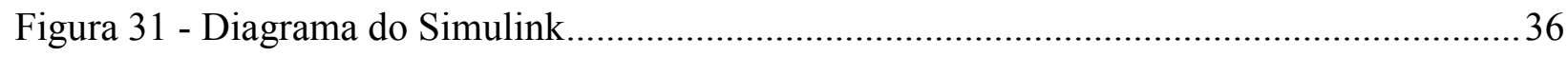

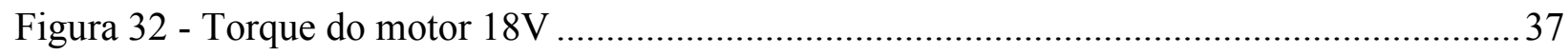

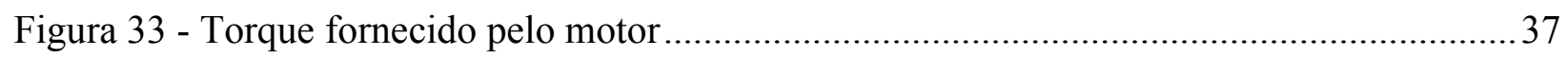

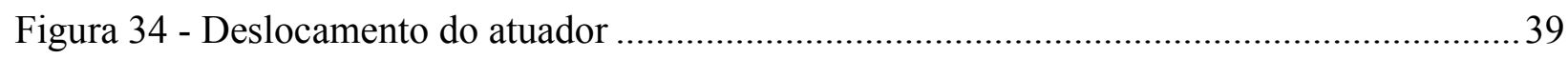

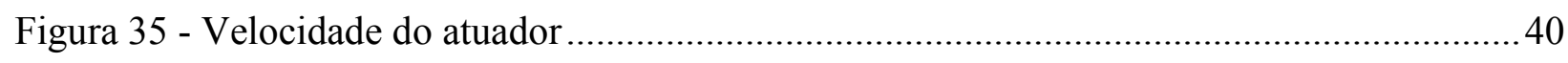

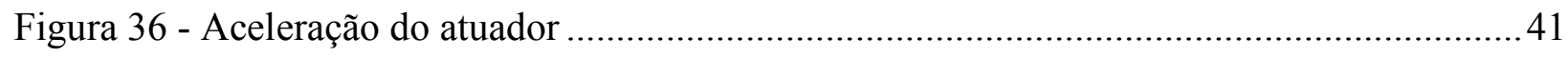

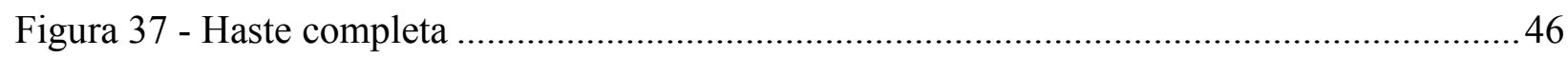

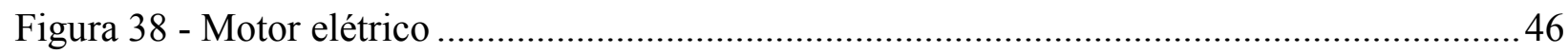

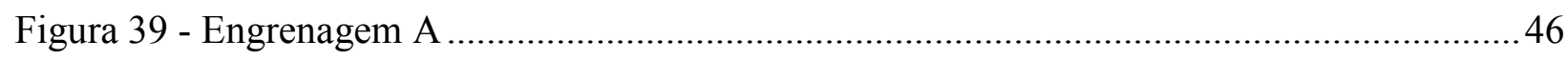

Figura 40 - Conjunto parafuso-rolamento-engrenagem C ................................................. 47

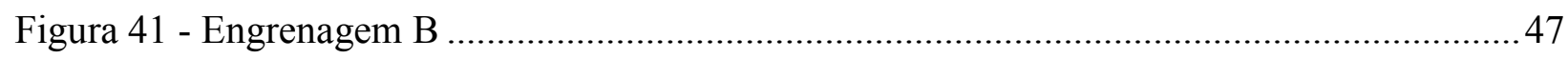

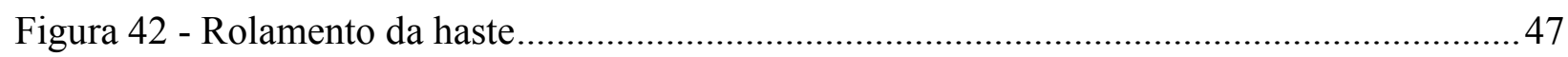

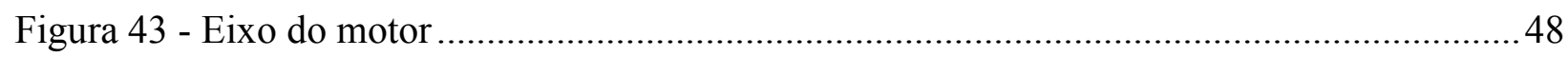

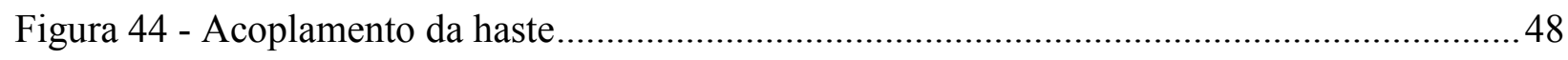

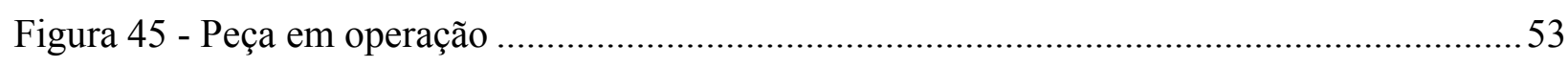

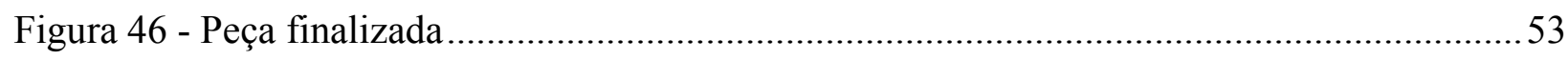


Figura 47 - Peça em operação

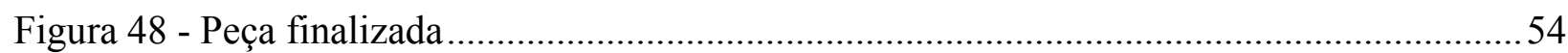




\section{Índice de tabelas}

Tabela 1 - Variáveis de potência e energia ........................................................................... 10

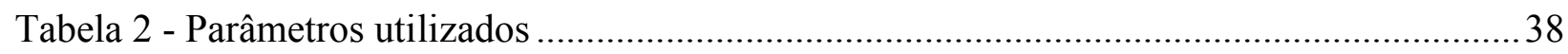




\section{Lista de símbolos}

Se Fonte de esforço

e Variável generalizada de esforço

$f \quad$ Variável generalizada de fluxo

TF Transformador

$p \quad$ Variável generalizada de momento

$q \quad$ Variável generalizada de deslocamento

1 Junção vetorial de fluxo comum

$z_{A} \quad$ Número de dentes da engrenagem $\mathrm{A}$

$Z_{B 1} \quad$ Número de dentes da engrenagem B1

$Z_{B 2} \quad$ Número de dentes da engrenagem B2

$z_{C} \quad$ Número de dentes da engrenagem $\mathrm{C}$

$\xi \quad$ Constante de amortecimento

I Momento de inércia

$I_{e q} \quad$ Momento de inércia equivalente

$R \quad$ Resistência

$\omega \quad$ Velocidade angular

$p \quad$ Passo do parafuso 
Ne Tipo de rosca

\section{Lista de abreviaturas}

CAD Desenho Auxiliado por Computador (Computer Aided Design)

CAM Computer Aided Manufacturing 


\section{Introdução}

\subsection{Objetivos}

Este trabalho apresenta um procedimento de modelagem e simulação em um atuador elétrico linear utilizando-se a metodologia de Grafos de Ligação. Essa técnica estabelece uma representação gráfica apropriada para a estrutura do modelo físico do sistema e contém uma formulação consistente para o desenvolvimento do modelo matemático.

Este estudo visa simular o comportamento dinâmico por diagramas de blocos, através do software Simulink. Sendo este último considerado como alternativa ao uso de programas específicos para esse método que são geralmente restritos. É apresentado também a modelagem tridimensional por meio da ferramenta Solidworks para obtenção do momento de inércia equivalente utilizado na solução das equações.

\subsection{Motivação}

O atuador linear elétrico pode ser integrado em modelos dinâmicos de mecanismos paralelos. Estes quando comparados a manipuladores em séries possuem boa capacidade de posicionamento, elevada capacidade de carga, grande rigidez estrutural, espaço de trabalho reduzido e baixa inércia.

As estruturas paralelas surgiram no início da década de 60, quando Gough e Witehall desenvolveram um sistema paralelo para uso em uma máquina de teste universal. Em 1965, 
Stewart elaborou uma plataforma para emprego em simuladores de voo e este foi um grande passo para esse mecanismo.

Esse trabalho surgiu como complemento da Tese de Doutorado do aluno de Pósgraduação Allan Nogueira de Albuquerque, que apresenta um procedimento para a determinação do modelo analítico de um mecanismo plano paralelo com três graus de liberdade por meio da caracterização do fluxo de energia entre seus componentes. São adotados os fundamentos, conceitos e elementos da técnica de Grafos de Ligação e assim, as equações analíticas tornam o processo de simulação e controle em tempo real desse sistema mais eficiente.

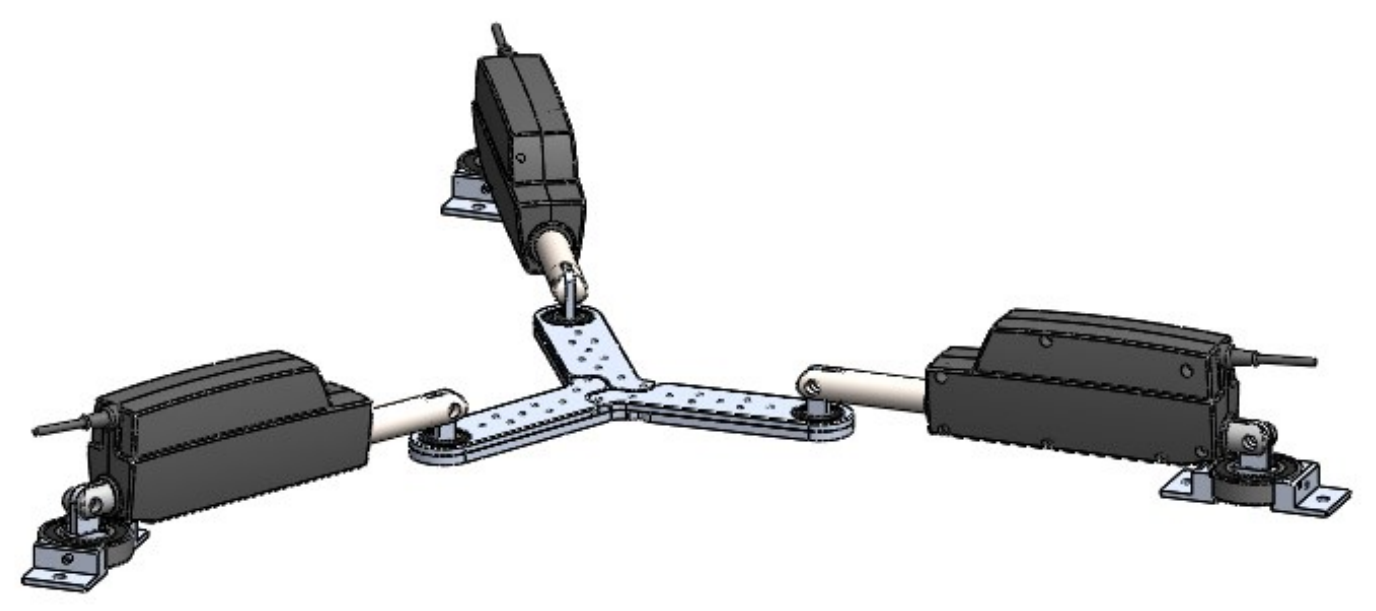

Figura 1 - CAD da plataforma plana 


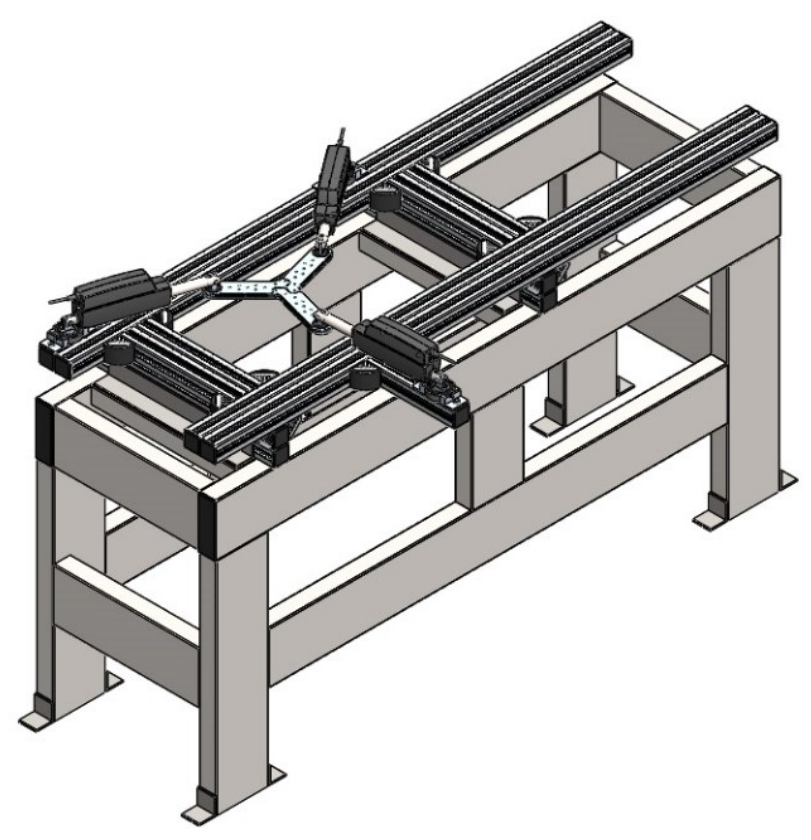

Figura 2 - CAD da bancada

\subsection{Revisão bibliográfica}

Esse tipo de atuador é o mais usado no âmbito industrial, pois combina as vantagens da energia elétrica - baixo custo, facilidade de transporte - com sua construção simples, custo reduzido, grande versatilidade de adaptação às cargas dos mais diversos tipos e melhores rendimentos.

Mesquita, A. C. (2009) desenvolveu um protótipo de atuador linear para executar as trocas de marcha automatizadas de um veículo de competição da categoria Fórmula SAE. Através desse trabalho, foi possível avaliar a viabilidade desses equipamentos eletromecânicos comparados aos pneumáticos. 
É visto também na área de bioengenharia, onde pode ser aplicado à prótese de membro superior, aferindo-se a sua capacidade de substituição do motor rotativo de acordo com as necessidades da aplicação. (Aline Juliani, 2011)

\subsection{Organização do trabalho}

O trabalho será composto por quatro partes.

Na segunda parte, Modelo do atuador elétrico linear, é apresentado o modelo em CAD do atuador linear elétrico simplificado e detalhado, a metodologia do Grafo de Ligação e seu respectivo modelo nesse método.

No capítulo 3 é apresentado o resultado das simulações computacionais realizadas por meio das ferramentas Matlab e Solidworks.

Baseado nos resultados encontrados no capítulo 3, o capítulo 4 apresenta as conclusões juntamente com as sugestões de trabalhos futuros. 


\section{Modelo do atuador linear elétrico}

\subsection{Introdução}

Atuadores lineares elétricos são dispositivos eletromecânicos que permitem a motorização de válvulas, dampers, entre outros equipamentos. Sua função principal é o controle do movimento da haste da válvula e o atuador por ser acoplado por meio de unidades de adaptação ou redutores.

Esse tipo de mecanismo possui movimentos rotacionais no eixo que são convertidos em movimentos lineares, utilizando-se engrenagens.

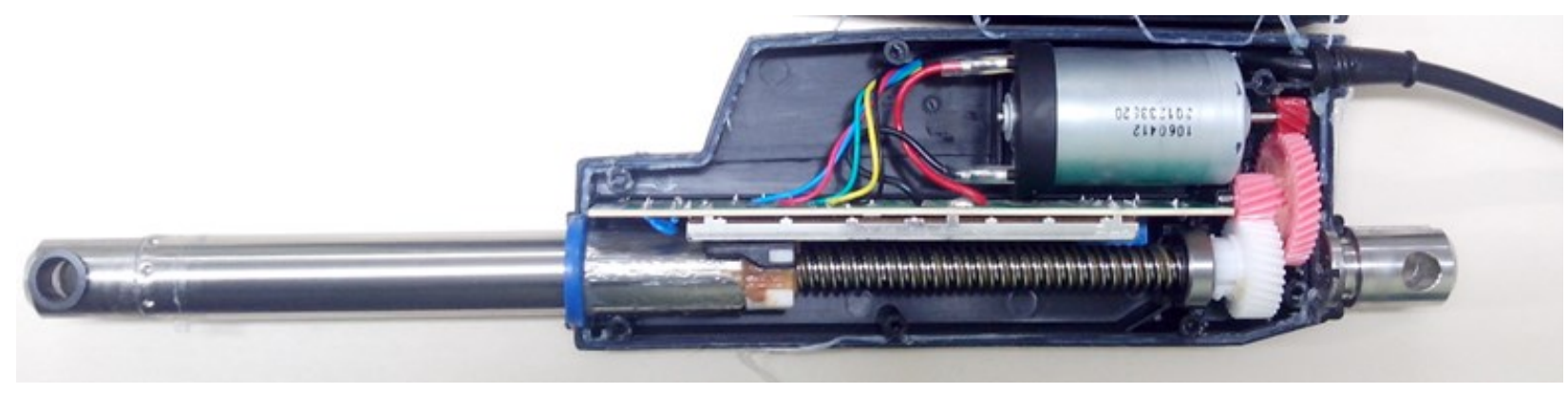

Figura 3 - Atuador Linak LA12 


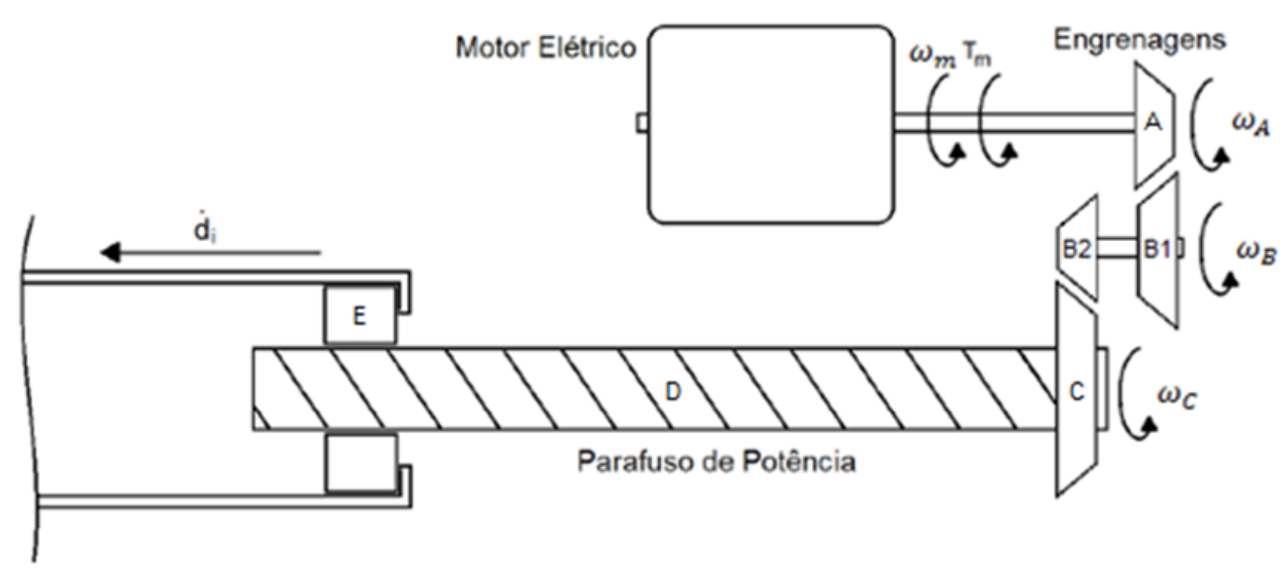

Figura 4 - Modelo esquemático do atuador

A figura 3 representa o interior do atuador linear elétrico LINAK LA12 e este dispositivo é utilizado como uma alternativa prática e econômica nos sistemas pneumáticos tradicionais e motores de engrenagem.

$\mathrm{Na}$ figura 4, observa-se um modelo esquemático de todos os componentes presentes. $\mathrm{O}$ motor elétrico transmite um torque $T_{m}$ que é convertido na velocidade angular $\omega_{m}$. A velocidade de rotação é transmitida às engrenagens e, posteriormente, ao parafuso de potência. Observa-se que a velocidade angular $\omega_{A}$ na engrenagem $\mathrm{A}$, com $z_{A}$ dentes, é a mesma velocidade do eixo do motor $\omega_{m}$. A transmissão da engrenagem A para engrenagem B1, com $z_{B 1}$ dentes, é $n_{A-B 1}={ }_{A} / z_{B 1}$. A engrenagem B2, com $Z_{B 2}$ dentes, possui a mesma velocidade angular de B1. A razão de transmissão das engrenagens $\mathrm{B} 2$ para $\mathrm{C}$, sendo este último com $z_{C}$ dentes, é $n_{B 2-C}=$ $Z_{B 2} / z_{C}$. O parafuso de potência d possui uma velocidade angular $\omega_{C}$. Acoplada a haste do atuador, o movimento da rosca de transporte torna-se linear com velocidade $\dot{d}$. Esta possui a relação $n_{p}=\frac{1}{2 \pi} p N e$, onde $\mathrm{p}$ é o passo do parafuso e Ne, o tipo de rosca. A razão total de transmissão do sistema é dado por $\dot{d}=n_{p} n_{A-B 1} n_{B 2-C} \omega_{m}$. 


\subsection{Modelo em CAD do atuador elétrico linear}

O atuador elétrico foi desenvolvido utilizando a ferramenta Solidworks, um programa de modelagem tridimensional. Com este software, pôde-se observar o comportamento do atuador para diferentes condições.

Inicialmente, elaborou-se um modelo simplificado constituído somente pelo corpo e haste (figuras 5 e 6). Em seguida, foi considerado o motor, as engrenagens e o parafuso de potência (figuras 7 e 8). As peças e montagens de cada modelo podem ser encontradas no CD Anexo.

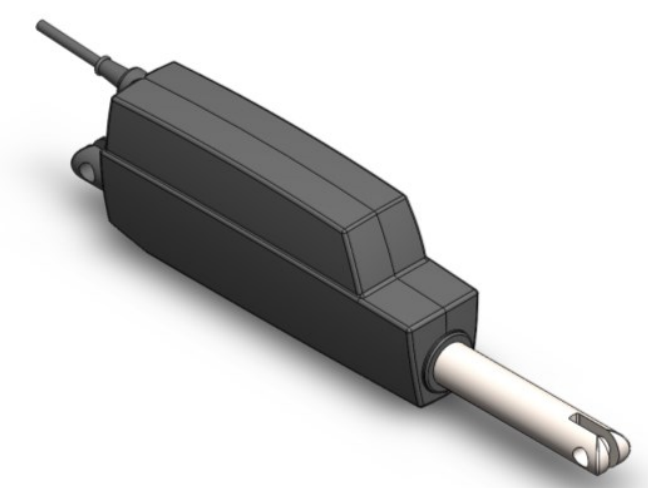

Figura 5 - Modelo simplificado do atuador 


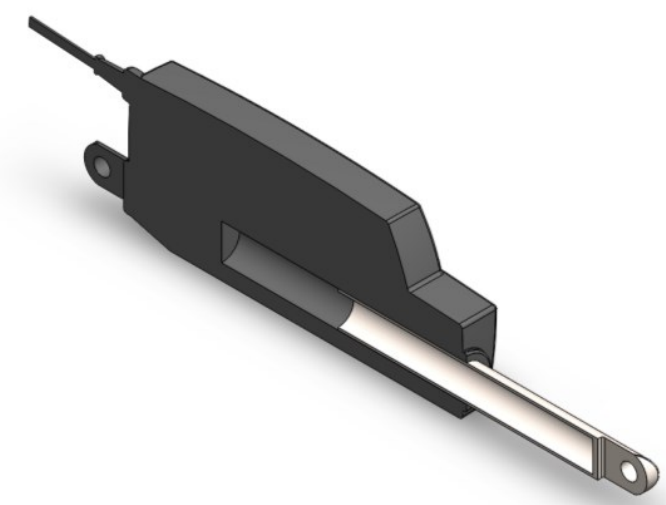

Figura 6 - Interior do atuador

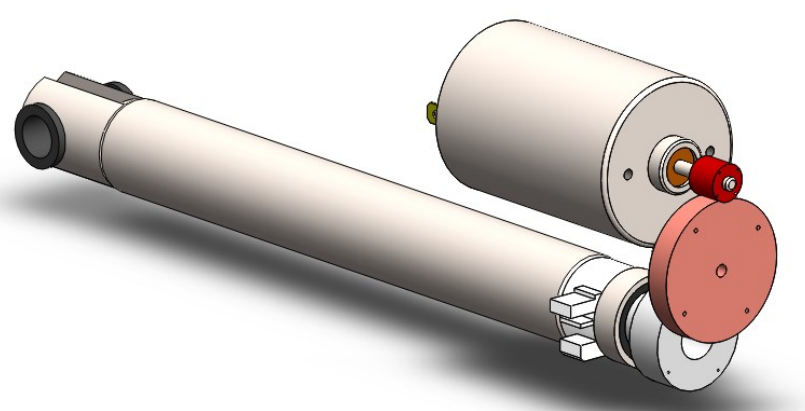

Figura 7 - Modelo detalhado do atuador

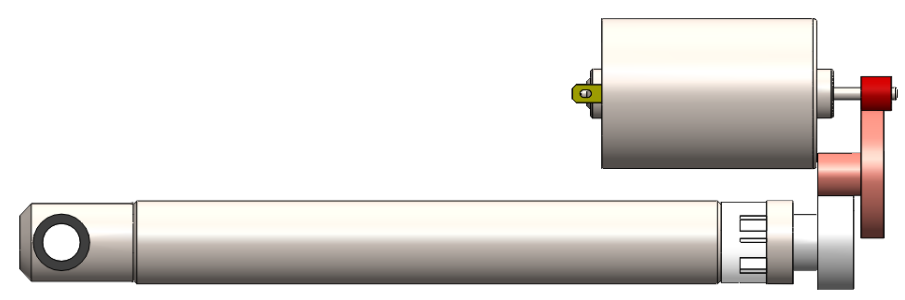

Figura 8 - Modelo do atuador detalhado (vista frontal) 


\subsection{Dinâmica do atuador elétrico linear via grafos de ligação}

A metodologia dos Grafos de Ligação surgiu no final da década de 50 e foi desenvolvida por Karnopp e Rosenberg (1968) desde a década de 1960. É uma técnica que pode incluir sistemas de naturezas físicas distintas como elétricos, mecânicos, hidráulicos, pneumáticos e térmicos; representar sistemas de parâmetros concentrados, lineares ou não; entre outros.

É estabelecido uma representação gráfica para a estrutura do modelo físico do sistema e possui uma formulação para o desenvolvimento do modelo matemático. Esse método possui como características: representação apropriada para as propriedades físicas dos elementos e para suas respectivas relações de causa e efeito.

Nove elementos básicos constituem essa técnica e são estes as fontes de esforço, fontes de fluxo, resistores, inércias, capacitores, transformadores, giradores e as junções “ 0 ” e "1". As ligações que conectam os componentes ou subsistemas representam o fluxo de potência entre eles. Nessa técnica são utilizados quatro tipos de variáveis generalizadas: as variáveis de potência - esforço (e) e fluxo (f) e as de energia - quantidade de movimento (p) e de deslocamento (q).

Motores em geral podem ser considerados, dentro de algumas hipóteses, como fontes de esforço. Tanto o conjunto de engrenagens quanto o parafuso, apresentam resistências $R_{6}, R_{10}$, $R_{14}$ e $R_{18}$ devido ao atrito viscoso e os elementos de inércia $I_{7}, I_{11}, I_{15}$ e $I_{19}$ pela massa dos corpos. 
A tabela 1 apresenta as variáveis de potência e energia em alguns domínios físicos que podem ser representados pelos grafos de ligação.

\section{Tabela 1 - Variáveis de potência e energia}

\begin{tabular}{|c|c|c|}
\hline & Esforço $e$ & Fluxo $f$ \\
\hline 1 & Torque fornecido pelo motor elétrico [N.m] & Velocidade angular [rad/s] \\
\hline 2 & $\begin{array}{l}\text { Torque no sentido oposto proveniente da perda de } \\
\text { energia do motor [N.m] }\end{array}$ & Velocidade angular [rad/s] \\
\hline 3 & Momento de inércia do motor [kg.m²] & Velocidade angular [rad/s] \\
\hline 4 & $\begin{array}{l}\text { Torque fornecido à engrenagem cilíndrica com dentes } \\
\text { oblíquos [N.m] }\end{array}$ & Velocidade angular [rad/s] \\
\hline 5 & $\begin{array}{l}\text { Torque fornecido pela engrenagem cilíndrica com } \\
\text { dentes oblíquos A [N.m] }\end{array}$ & Velocidade angular [rad/s] \\
\hline 6 & $\begin{array}{l}\text { Torque no sentido oposto proveniente da perda de } \\
\text { energia da engrenagem cilíndrica com dentes oblíquos } \\
\text { A [N.m] }\end{array}$ & Velocidade angular [rad/s] \\
\hline 7 & $\begin{array}{l}\text { Momento de inércia da engrenagem cilíndrica com } \\
\text { dentes oblíquos A [N.m] }\end{array}$ & Velocidade angular [rad/s] \\
\hline 8 & $\begin{array}{l}\text { Torque fornecido à engrenagem cilíndrica com dentes } \\
\text { oblíquos B [N.m] }\end{array}$ & Velocidade angular [rad/s] \\
\hline 9 & $\begin{array}{l}\text { Torque fornecido pela engrenagem cilíndrica com } \\
\text { dentes oblíquos B [N.m] }\end{array}$ & Velocidade angular [rad/s] \\
\hline 10 & $\begin{array}{l}\text { Torque no sentido oposto proveniente da perda de } \\
\text { energia da engrenagem cilíndrica com dentes oblíquos } \\
\text { B [N.m] }\end{array}$ & Velocidade angular [rad/s] \\
\hline
\end{tabular}




\begin{tabular}{|l|l|l|}
\hline 11 & $\begin{array}{l}\text { Momento de inércia da engrenagem cilíndrica com } \\
\text { dentes oblíquos B [N.m] }\end{array}$ & Velocidade angular [rad/s] \\
\hline 12 & $\begin{array}{l}\text { Torque fornecido à engrenagem cilíndrica com dentes } \\
\text { oblíquos C [N.m] }\end{array}$ & Velocidade angular [rad/s] \\
\hline 13 & $\begin{array}{l}\text { Torque fornecido pela engrenagem cilíndrica com } \\
\text { dentes oblíquos C [N.m] }\end{array}$ & Velocidade angular [rad/s] \\
\hline 14 & $\begin{array}{l}\text { Torque no sentido oposto proveniente da perda de } \\
\text { energia da engrenagem cilíndrica com dentes oblíquos } \\
\text { C [N.m] }\end{array}$ & Velocidade angular [rad/s] \\
\hline 15 & $\begin{array}{l}\text { Momento de inércia da engrenagem cilíndrica com } \\
\text { dentes oblíquos C [N.m] }\end{array}$ & Velocidade angular [rad/s] \\
\hline 16 & Torque fornecido ao parafuso de movimento [N.m] & Velocidade angular [rad/s] \\
\hline 17 & Força do parafuso de movimento [N] & Felocidade [m/s] \\
\hline 18 & Força oposta proveniente da perda de energia do & Velocidade associada ao \\
parafuso [N] & elemento resistor [m/s] \\
\hline 19 & Volemento inércia [m/s] \\
\hline
\end{tabular}

A representação gráfica permite a visualização das ligações entre os vários elementos do sistema (figura 9). 


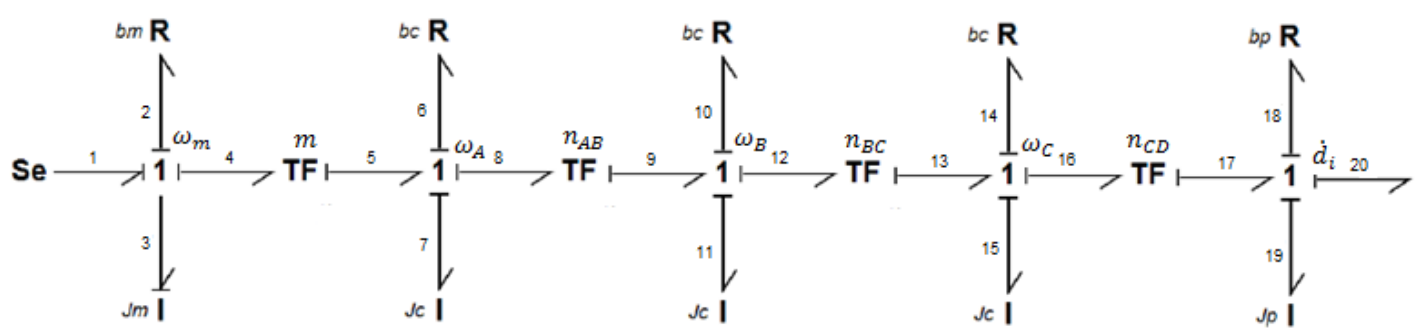

Figura 9 - Grafo de ligação

Os conjuntos de equações 2.1, 2.2, 2.3, 2.4 e 2.5 descrevem cada junção 1 . Nota-se que a quantidade de movimento $p_{7}$ possui causalidade natural. Já a equação 2.6 apresenta a equação diferencial que descreve a dinâmica do sistema.

$$
\begin{gathered}
\left\{\begin{array}{c}
f_{1}=f_{2}=f_{3}=f_{4} \\
e_{1}=e_{2}+e_{3}+e_{4} \\
e_{2}=R_{2} f_{2} \\
\dot{p}_{3}=e_{3} \\
f_{3}=\frac{1}{I_{3}} p_{3} \\
e_{4}=m e_{5} \\
f_{5}=m f_{4}
\end{array}\right. \\
\left\{\begin{array}{c}
f_{5}=f_{6}=f_{7}=f_{8} \\
e_{5}=e_{6}+e_{7}+e_{8} \\
e_{6}=R_{6} f_{6} \\
\dot{p}_{7}=e_{7} \\
p_{7}=I_{7} f_{7} \\
e_{8}=n_{A B} e_{9} \\
f_{9}=n_{A B} f_{8}
\end{array}\right.
\end{gathered}
$$




$$
\begin{aligned}
& \left\{\begin{array}{c}
f_{9}=f_{10}=f_{11}=f_{12} \\
e_{9}=e_{10}+e_{11}+e_{12} \\
e_{10}=R_{10} f_{10} \\
e_{11}=\dot{p}_{11} \\
p_{11}=I_{11} f_{11} \\
e_{12}=n_{B C} e_{13} \\
f_{13}=n_{B C} f_{12}
\end{array}\right. \\
& \left\{\begin{array}{c}
f_{13}=f_{14}=f_{15}=f_{16} \\
e_{13}=e_{14}+e_{15}+e_{16} \\
e_{14}=R_{14} f_{14} \\
e_{15}=\dot{p}_{15} \\
p_{15}=I_{15} f_{15} \\
e_{16}=n_{C D} e_{17} \\
f_{17}=n_{C D} f_{16}
\end{array}\right. \\
& \left\{\begin{array}{c}
f_{17}=f_{18}=f_{19}=f_{20} \\
e_{17}=e_{18}+e_{19}+e_{20} \\
e_{18}=R_{18} f_{18} \\
e_{19}=\dot{p}_{19} \\
p_{19}=I_{19} f_{19}
\end{array}\right. \\
& \dot{p}_{3}=\left(-\frac{R_{2}+m^{2} R_{6}+m n_{A B}^{2} R_{10}+m^{2} n_{A B}^{2} n_{B C}^{2} R_{14}+m^{2} n_{A B}^{2} n_{B C}^{2} n_{C D}^{2} R_{18}}{I_{3}+m^{2} I_{7}+m^{2} n_{A B}^{2} I_{11}+m^{2} n_{A B}^{2} n_{B C}^{2} I_{15}+m^{2} n_{A B}^{2} n_{B C}^{2} n_{C D}^{2} I_{19}}\right) p_{3} \\
& +\frac{I_{3} e_{1}}{I_{3}+m^{2} I_{7}+m^{2} n_{A B}^{2} I_{11}+m^{2} n_{A B}^{2} n_{B C}^{2} I_{15}+m^{2} n_{A B}^{2} n_{B C}^{2} n_{C D}^{2} I_{19}} \\
& -\frac{I_{3} m n_{A B} n_{B C} n_{C D} e_{20}}{I_{3}+m^{2} I_{7}+m^{2} n_{A B}^{2} I_{11}+m^{2} n_{A B}^{2} n_{B C}^{2} I_{15}+m^{2} n_{A B}^{2} n_{B C}^{2} n_{C D}^{2} I_{19}}
\end{aligned}
$$

Quando o atuador for acoplado ao mecanismo plano paralelo, suas causalidades serão alteradas, figura 10. Com isso, seu equacionamento será modificado (Eq. 2.7). 


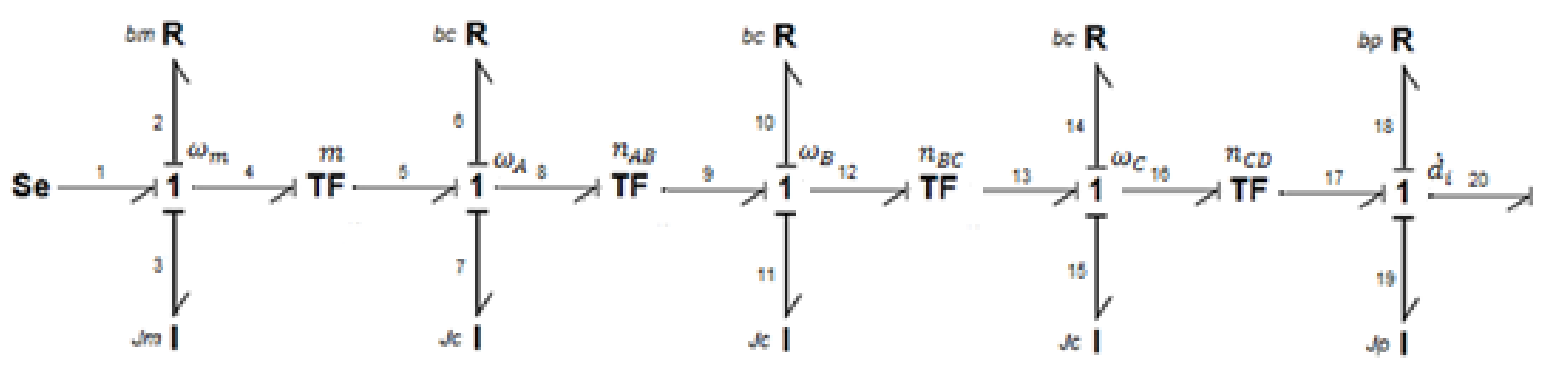

Figura 10 - Grafo de ligação com causalidade forçada

$$
\begin{gathered}
e_{20}=\frac{e_{1}}{m n_{A B} n_{B C} n_{C D}}-\left(\frac{R_{2}}{m^{2} n_{A B}^{2} n_{B C}^{2} n_{C D}^{2}}+\frac{R_{6}}{n_{A B}^{2} n_{B C}^{2} n_{C D}^{2}}+\frac{R_{10}}{n_{B C}^{2} n_{C D}^{2}}+\frac{R_{14}}{n_{C D}^{2}}\right. \\
\left.+R_{18}\right) f_{20}-\left(\frac{I_{3}}{m^{2} n_{A B}^{2} n_{B C}^{2} n_{C D}^{2}}+\frac{I_{7}}{n_{A B}^{2} n_{B C}^{2} n_{C D}^{2}}+\frac{I_{11}}{n_{B C}^{2} n_{C D}^{2}}+\frac{I_{15}}{n_{C D}^{2}}\right. \\
\left.+I_{19}\right) \dot{f}_{20}
\end{gathered}
$$

Para realizar as simulações no MATLAB, o Grafo de Ligação do atuador será simplificado considerando o conjunto motor-engrenagens e parafuso de potência. As equações 2.8 e 2.9 representam cada junção 1 e a 2.10 , a combinação entre elas.

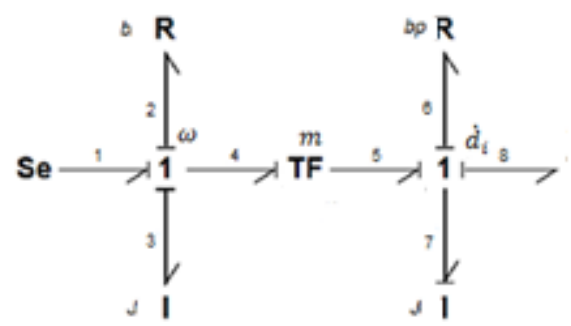

Figura 11 - Grafo de ligação simplificado 


$$
\begin{aligned}
& \left\{\begin{array}{c}
f_{1}=f_{2}=f_{3}=f_{4} \\
e_{1}=e_{2}+e_{3}+e_{4} \\
e_{2}=R_{2} f_{2} \\
\dot{p}_{3}=e_{3} \\
f_{3}=\frac{1}{I_{3}} p_{3} \\
e_{4}=m e_{5} \\
f_{5}=m f_{4}
\end{array}\right. \\
& \left\{\begin{array}{c}
f_{5}=f_{6}=f_{7}=f_{8} \\
e_{5}=e_{6}+e_{7}+e_{8} \\
e_{6}=R_{6} f_{6} \\
\dot{p}_{7}=e_{7} \\
p_{7}=I_{7} f_{7}
\end{array}\right. \\
& f_{7}=\left(\frac{m}{I_{3}+m^{2} I_{7}}\right) e_{1}-\left(\frac{R_{2}+R_{6} m^{2}}{I_{3}+m^{2} I_{7}}\right) f_{7}
\end{aligned}
$$

\subsection{Momento de inércia equivalente do conjunto motor-engrenagem}

Considerado o modelo simplificado constituído pela equação 2.10 , foi necessário obter o momento de inércia equivalente do conjunto motor-engrenagem.

O momento de inércia pode ser definido como um corpo de forma arbitrária, de massa M, girando livremente em torno de um eixo arbitrário, representado na figura 12. 


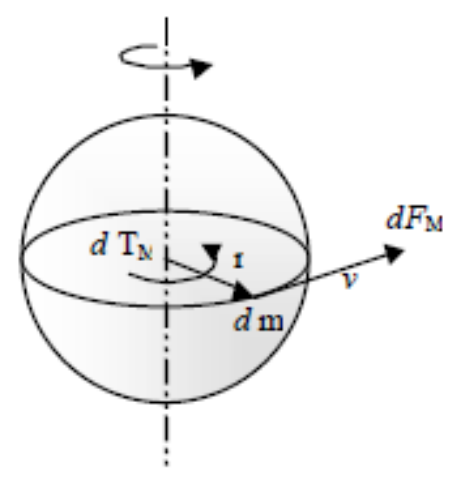

Figura 12 - Corpo de massa M girando livremente em torno de um eixo estabelecido

Assumindo que o corpo em movimento seja rígido, toda massa se move com a mesma velocidade angular. (Moreira F. A.)

$$
I=\int_{0}^{m} r^{2} d m
$$

Há sistemas com variação de velocidade - como mostrado neste trabalho. Com isto, redutores de velocidade e engrenagens são elementos essenciais para adequar a velocidade da máquina acionada com velocidade do motor.

$\mathrm{Na}$ figura 13, está presente um sistema de engrenagem ideal. Neste caso são considerados fricção nula, folga nula e escorregamento nulo. (Moreira F. A.) 


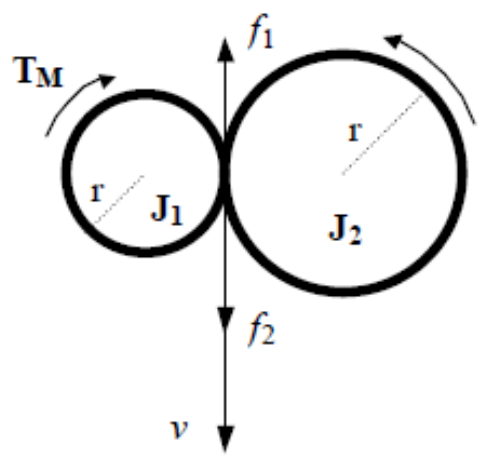

Figura 13 - Sistema de engrenagem ideal

Pelo equilíbrio de forças no ponto de contato das engrenagens $\left(f_{1}=f_{2}\right)$, igualou-se os binários motor e máquina (equações 2.12 e 2.13). Como a velocidade linear é idêntica no contato, obtém-se a equação 2.14. Já associando as equações 2.12, 2.13 e 2.14, obtém-se a equação 2.15 .

$$
\begin{aligned}
& T_{M}-r_{1} f_{1}=J_{1} \frac{d \omega}{d t} \\
& r_{2} f_{2}=J_{2} \frac{d \omega}{d t} \\
& v=r_{1} \omega_{1}=r_{2} \omega_{2}
\end{aligned}
$$




$$
T_{M}=\left[J_{1}+\left(\frac{r_{1}}{r_{2}}\right)^{2} J_{2}\right] \frac{d \omega_{1}}{d t}
$$

Onde se verifica que a inércia $J_{2}$, com velocidade $\omega_{2}$, se aproxima à inércia $J_{1}$, no eixo de velocidade $\omega_{1}$. A relação dada entre as inércias é dada pela equação 2.16.

$$
\left(\frac{r_{1}}{r_{2}}\right)^{2}=\left(\frac{\omega_{2}}{\omega_{1}}\right)^{2}=i^{2}
$$

Sendo $i$, a relação de transmissão do sistema de engrenagens. Logo, a inércia equivalente referida ao eixo 1 é dada pela equação 2.17 .

$$
I_{e q}=I_{1}+I_{2}\left(\frac{\omega_{2}}{\omega_{1}}\right)^{2}
$$

O elemento $I_{e q}$ é composto de uma componente que corresponde à sua própria inércia $I_{1}$ e de uma componente refletida da engrenagem 2. A partir da teoria, é possível encontrar a inércia equivalente do conjunto motor-engrenagem (equação 2.18).

$$
I_{e q}=I_{1}+I_{2}\left(\frac{r_{A}}{r_{B 1}}\right)^{2}+I_{3}\left(\frac{r_{B 2}}{r_{C}}\right)^{2}
$$


Onde $I_{1}$ corresponde ao momento de inércia do conjunto eixo do motor + engrenagem $\mathrm{A} ; I_{2}$, a engrenagem $\mathrm{B} 1$ e B2 e $I_{3}$, a engrenagem $\mathrm{C}$ e parafuso de potência.

\subsection{Curvas características do motor}

Para determinar a curva característica do motor elétrico presente no atuador, o aluno Alessandro Soares realizou testes experimentais em diferentes voltagens (6, 12, 18 e 24V). Tal teste colaborou para obter a resposta do torque no tempo.

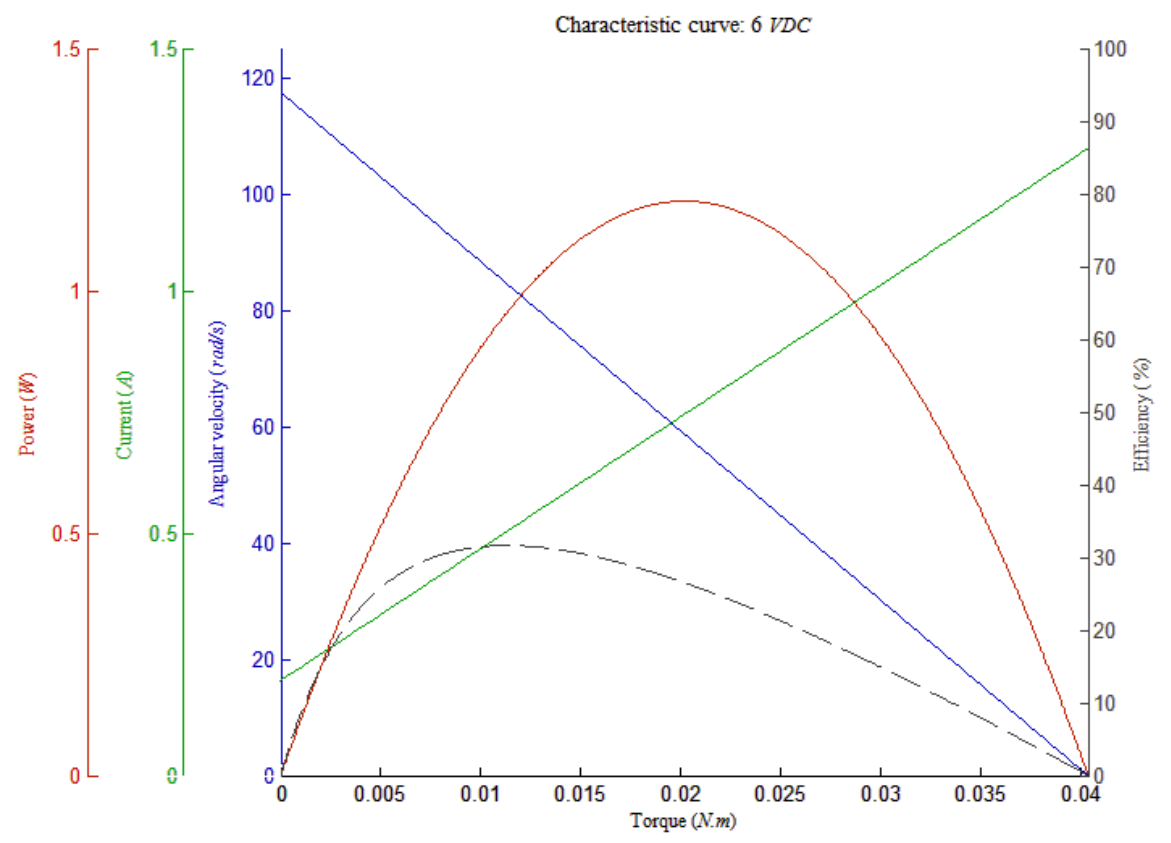

Figura 14 - Curva característica 6 VDC 


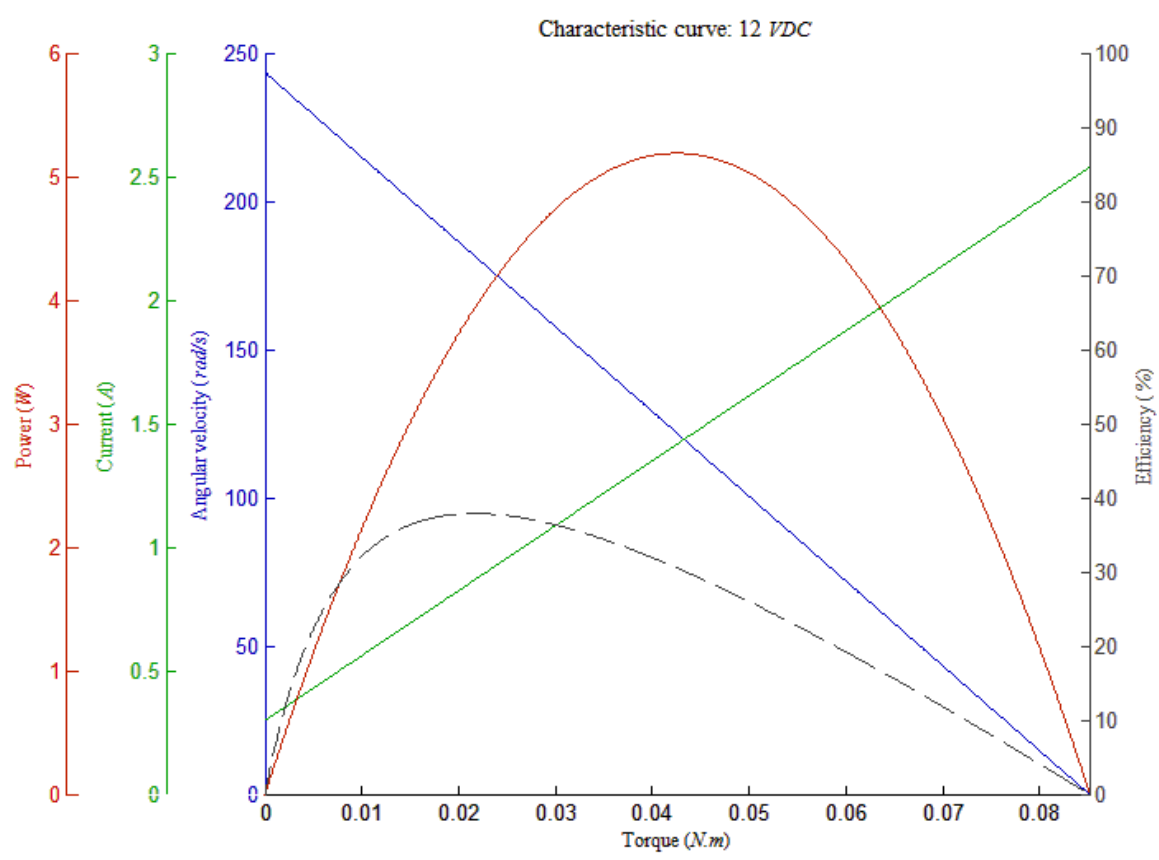

Figura 15 - Curva característica 12 VDC

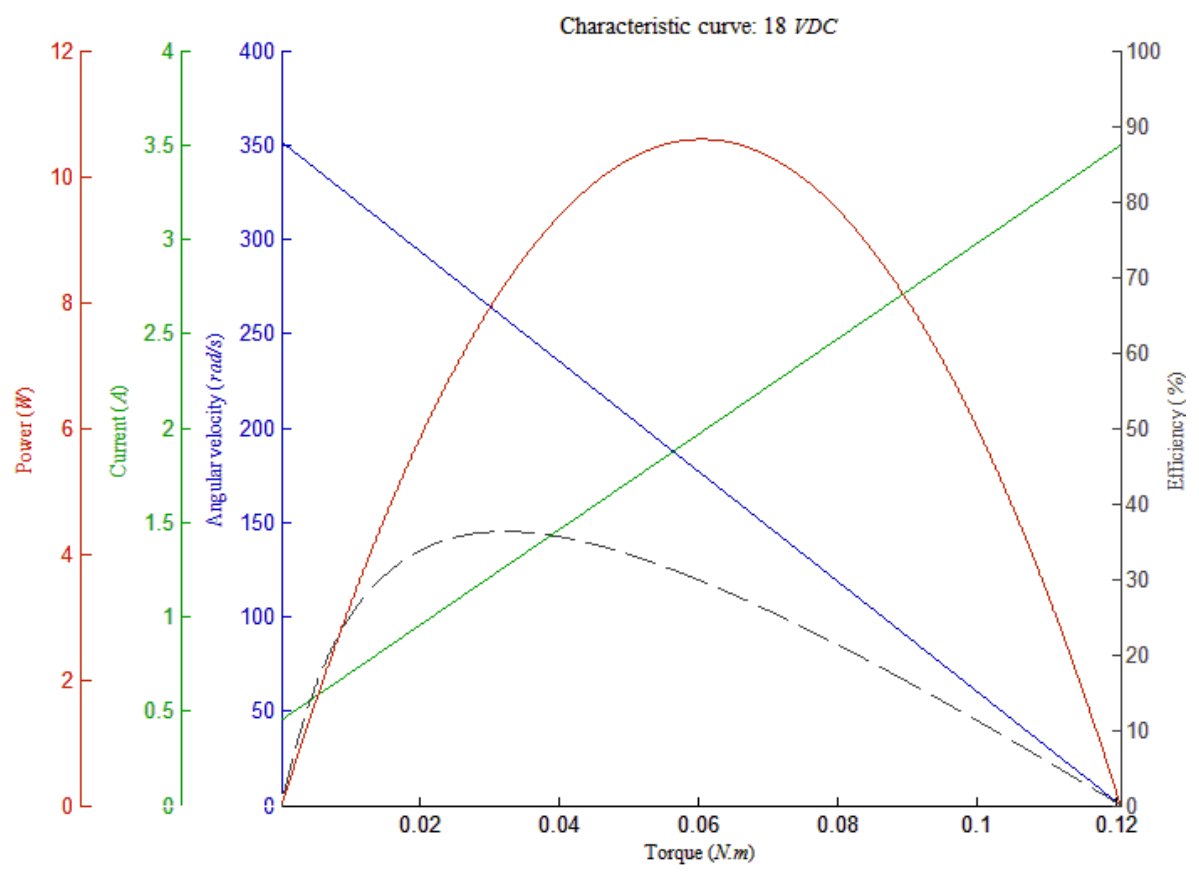

Figura 16 - Curva característica 18 VDC 


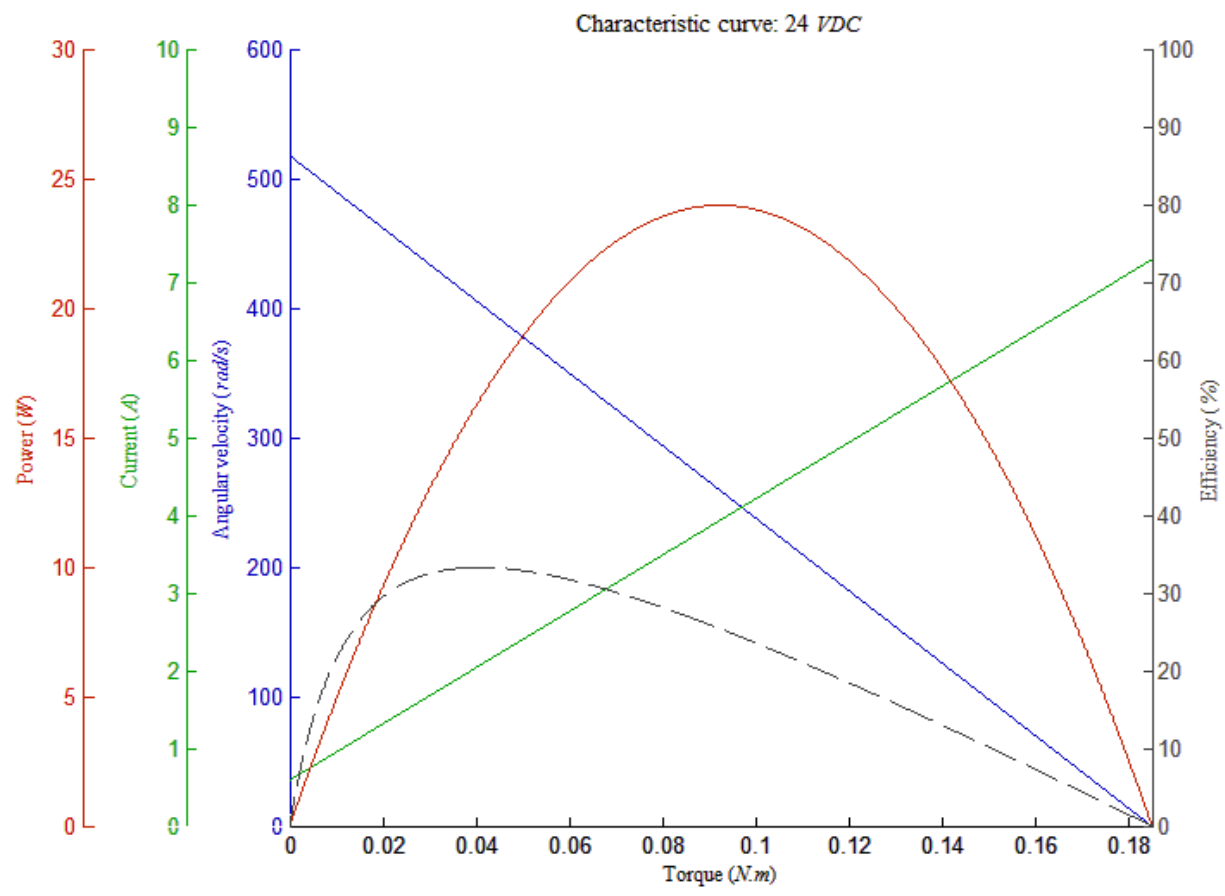

Figura 17 - Curva característica 24 VDC 


\section{Simulações para avaliação dos modelos desenvolvidos}

\subsection{Introdução}

Para a análise do comportamento do atuador, são propostas simulações para os respectivos modelos elaborados. As ferramentas utilizadas são o SolidWorks Motion e o Matlab/Simulink. O primeiro é destinado para compreender o desempenho dos modelos em movimento. É possível especificar molas e amortecedores; adicionar gravidade ao sistema e contato entre os componentes; dimensionar motores; visualizar graficamente e analiticamente todos os resultados. Isto resulta em uma redução quantitativa nos custos em prototipagem física e no tempo de desenvolvimento de produto.

Já o segundo, utiliza uma interface gráfica que permite a construção dos modelos a partir de diagramas de blocos, aplicado a sistemas lineares ou não, contínuos e/ou discreto no tempo. Os resultados obtidos podem ser exportados para o MATLAB para visualização ou um novo processamento.

\subsection{Simulações em SolidWorks Motion}

A Análise de Movimento do SolidWorks (SolidWorks Motion) permite que dois tipos de problemas relacionados com o movimento dos corpos sólidos sejam estudados: a Cinemática, estudo do movimento de um corpo rígido sem considerar as forças que resultam neste movimento, e a Dinâmica, estudo do movimento de um corpo rígido como um resultado das cargas aplicadas sobre o corpo. Estas cargas podem ser forças e/ou torque externos (fontes de 
esforços) e, também como entradas do sistema, podem ser inseridos motores lineares ou rotativos ideais (fontes de fluxo). Outros elementos que podem ser inseridos são molas (elementos resistores do sistema), amortecedores (elementos capacitores do sistema) e as massas e momentos de inércias que são incorporadas do próprio modelo desenvolvido em CAD (elementos de inércia do sistema). Assim, a simulação do SolidWorks Motion pode calcular o efeito destes elementos, da ação da gravidade e do contato entre os componentes (via inserção de coeficientes de atrito nas superfícies do modelo; Nizar, M. H. M., 2013).

No ambiente de simulação, um corpo rígido sem restrições no espaço tem seis graus de liberdade: três translacionais e três rotacionais. Este pode mover-se ao longo dos eixos X, Y, e Z e rotacionar em torno destes eixos. Porém, restrições podem ser impostas para adequar o modelo às restrições sistema real ou até mesmo para simplificar uma simulação. Um conjunto de equações diferenciais e equações algébricas definem as equações de movimento do SolidWorks Motion. A solução numérica destas equações é obtida pela integração destas equações diferenciais enquanto são satisfeitas as restrições algébricas em cada passo do tempo da simulação. Com esta ferramenta, também podem ser detectadas interferências mecânicas nos modelos simulados durante o movimento analisado.

As entradas do sistema podem ser valores constantes, funções no tempo ou até mesmo dados interpolados de uma curva de desempenho de um atuador, por exemplo. Podem ser escolhidos três métodos de interpolação: interpolação Akima (Akima, H., 1970), cúbica ou linear. 


\subsubsection{Modelo simplificado}

Para estudar o comportamento do modelo simplificado, adicionou-se uma mola linear com as constantes de rigidez iguais a $1,3 \mathrm{~N} / \mathrm{mm}, 2,6 \mathrm{~N} / \mathrm{mm}$ ou $5,2 \mathrm{~N} / \mathrm{mm}$ e um amortecedor linear com as constantes de amortecimento iguais a $0,01 \mathrm{~N} /(\mathrm{mm} / \mathrm{s}), 0,1 \mathrm{~N} /(\mathrm{mm} / \mathrm{s})$ ou $1 \mathrm{~N} /(\mathrm{mm} / \mathrm{s})$. Em seguida, foi aplicado uma força constante de $100 \mathrm{~N}$.

A mola opõe-se à força que a ela está aplicada, armazenando energia potencial elástica e sua rigidez possui como representação a força por unidade de deslocamento, ou seja, a força requerida para produzir um deslocamento unitário na mola.

Um amortecedor é o componente que dissipa energia mecânica do sistema. A energia é consumida por atrito entre as peças móveis do sistema e/ou pelo atrito interno entre as moléculas das peças do sistema, havendo uma dissipação de energia mecânica sob forma de calor e/ou som.

Figura 18 - Atuador com uma mola e um amortecimento linear 
Inicialmente, foram realizadas simulações com as constantes de rigidez mencionadas e $\xi$ igual a $0,01 \mathrm{~N} /(\mathrm{mm} / \mathrm{s})$. Os gráficos de deslocamento, velocidade e aceleração deste primeiro caso estão representados nas figuras 19, 20 e 21, respectivamente.
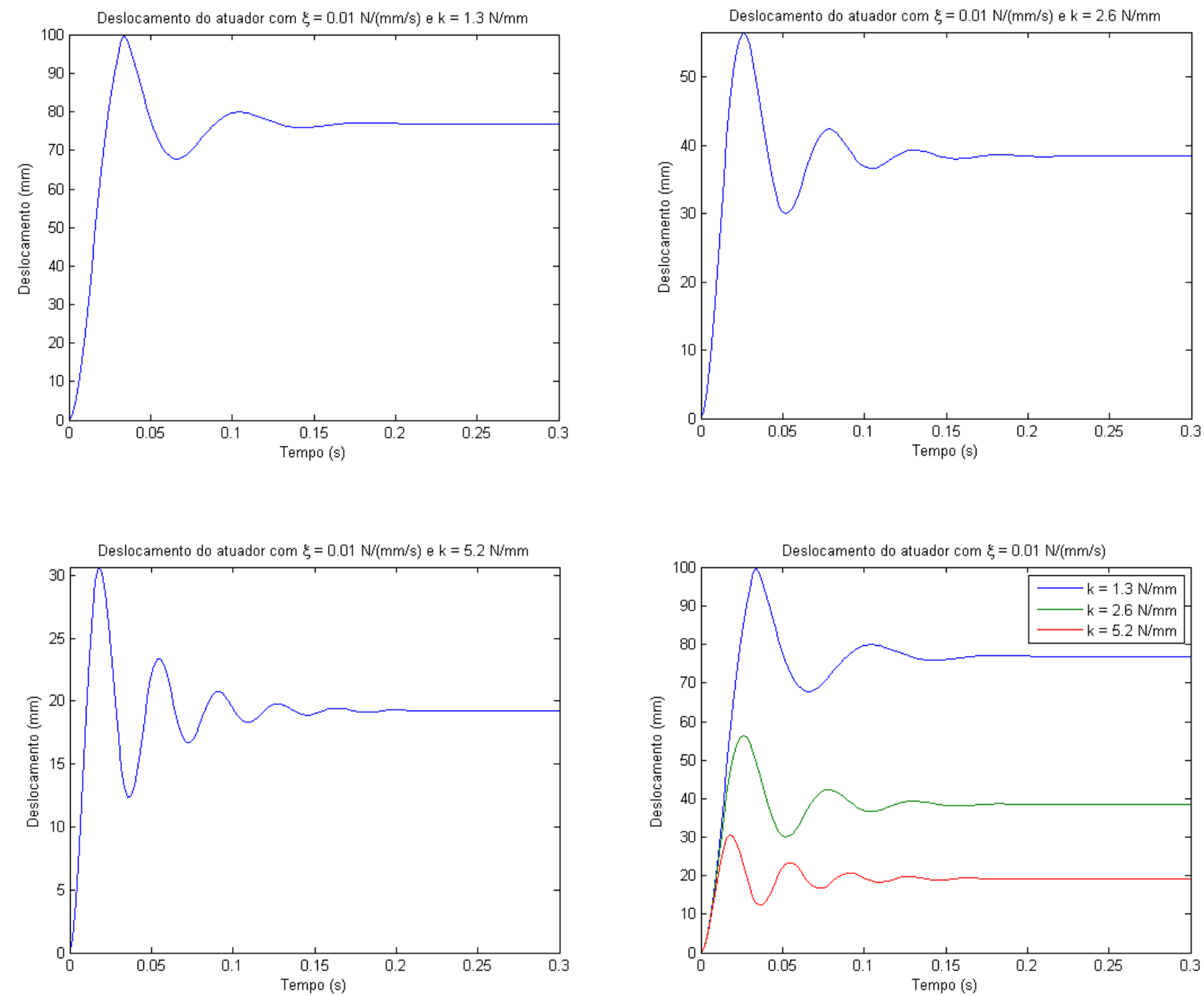

Figura 19 - Deslocamento do atuador com $\xi=0,01 \mathrm{~N} /(\mathrm{mm} / \mathrm{s})$

A figura 19 indica um movimento oscilatório amortecido devido a diminuição da amplitude provocada pelo amortecedor. A expressão que representa esse movimento é composta pelo produto de uma função exponencial decrescente por uma função harmônica. Esta última é 
oscilatória devido a presença de senos e cossenos, porém a função exponencial decrescente faz com que haja uma diminuição da amplitude da harmônica à medida que o tempo cresce.
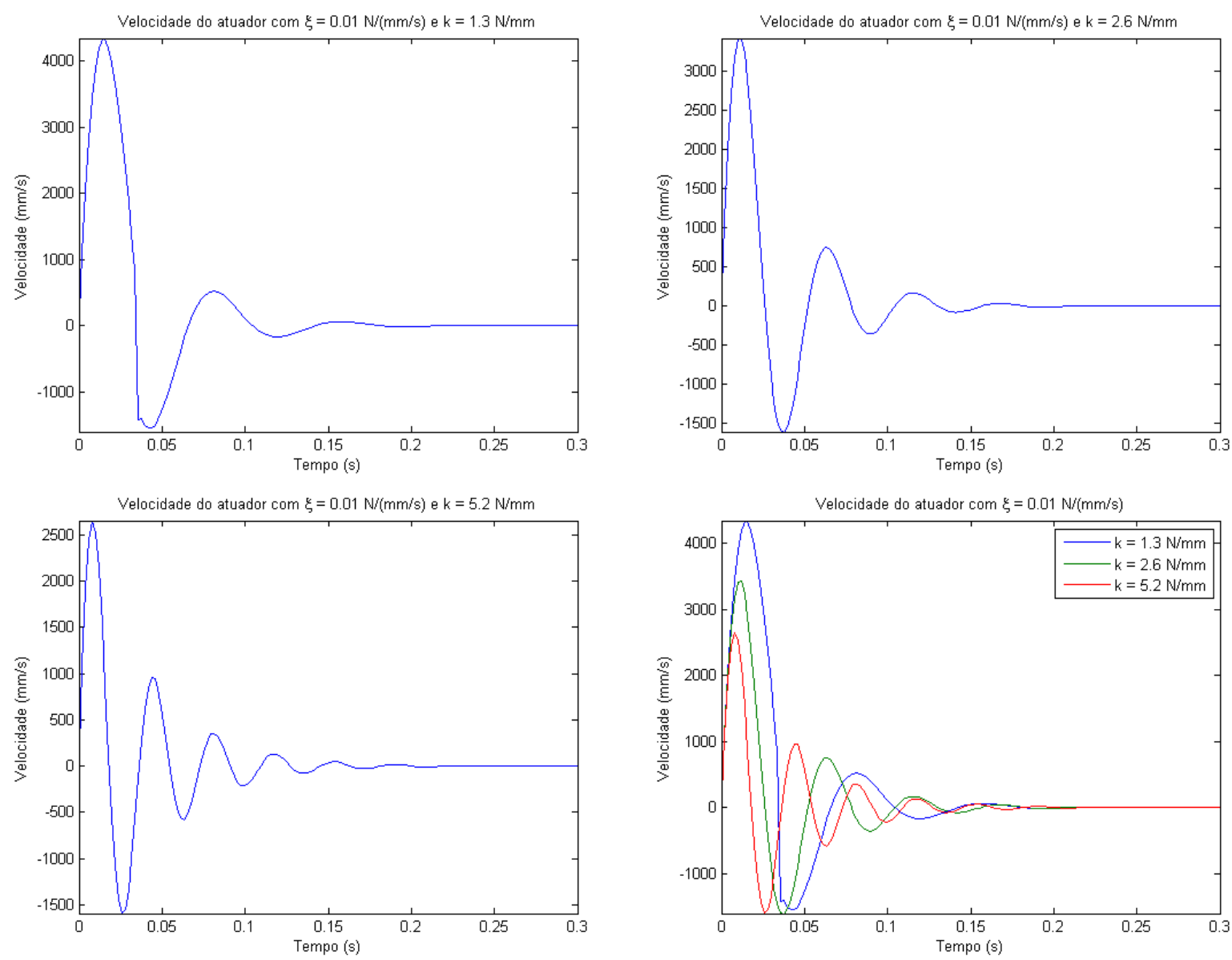

Figura 20 - Velocidade do atuador com $\xi=0,01 \mathrm{~N} /(\mathrm{mm} / \mathrm{s})$

$\mathrm{Na}$ figura 20 é observado que a haste do atuador oscila mais na maior constante de rigidez e a maior velocidade é atingida no caso com a menor constante de rigidez. 

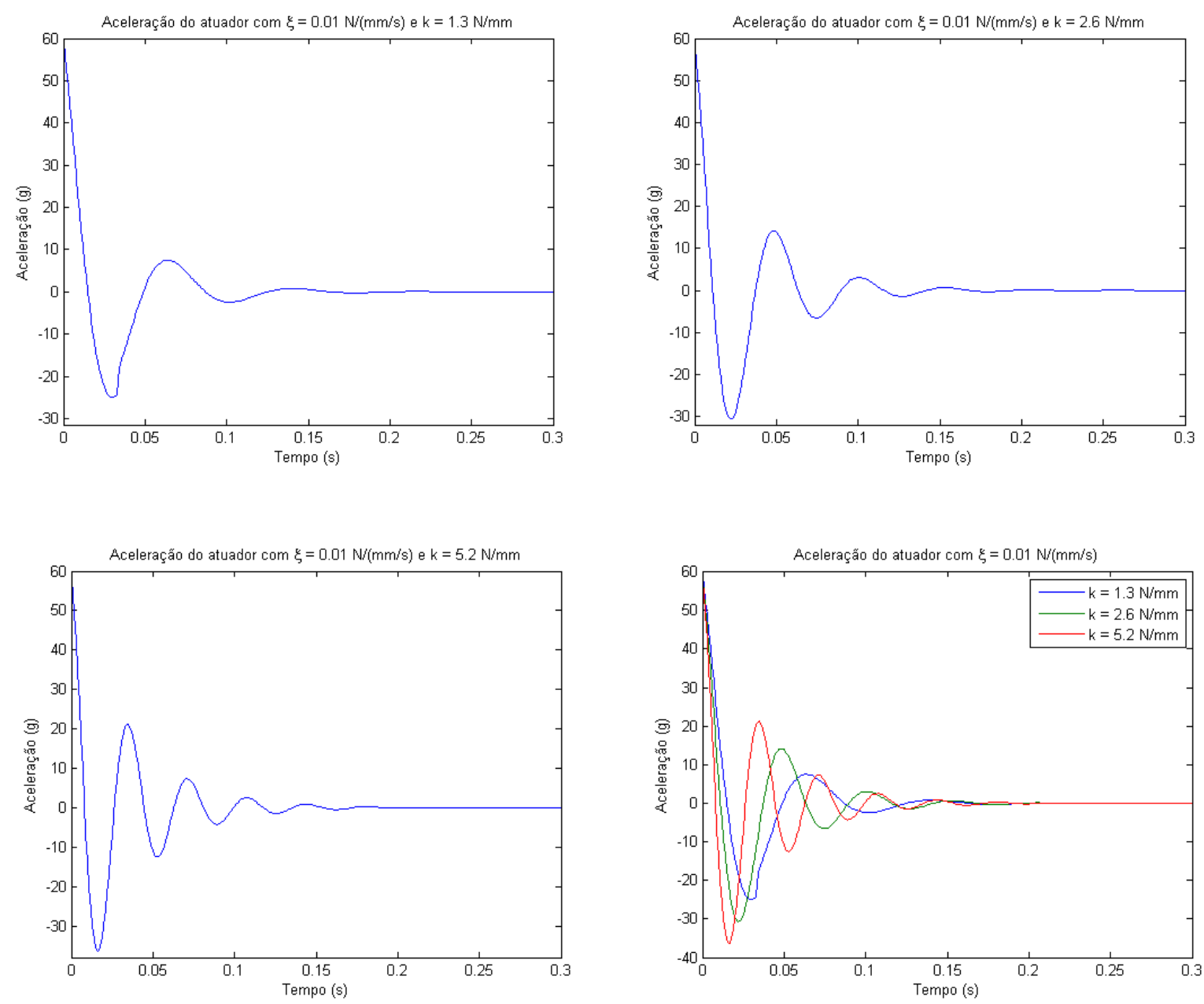

Figura 21 - Aceleração do atuador com $\xi=0,01 \mathrm{~N} /(\mathrm{mm} / \mathrm{s})$

A figura 21 indica que a aceleração máxima é obtida quando a haste atinge sua maior velocidade.

No segundo caso, altera-se somente a constante de amortecimento para $\xi=0,1$ $\mathrm{N} /(\mathrm{mm} / \mathrm{s})$. Os gráficos de deslocamento, velocidade e aceleração deste primeiro caso estão representados nas figuras 22,23 e 24, respectivamente. 

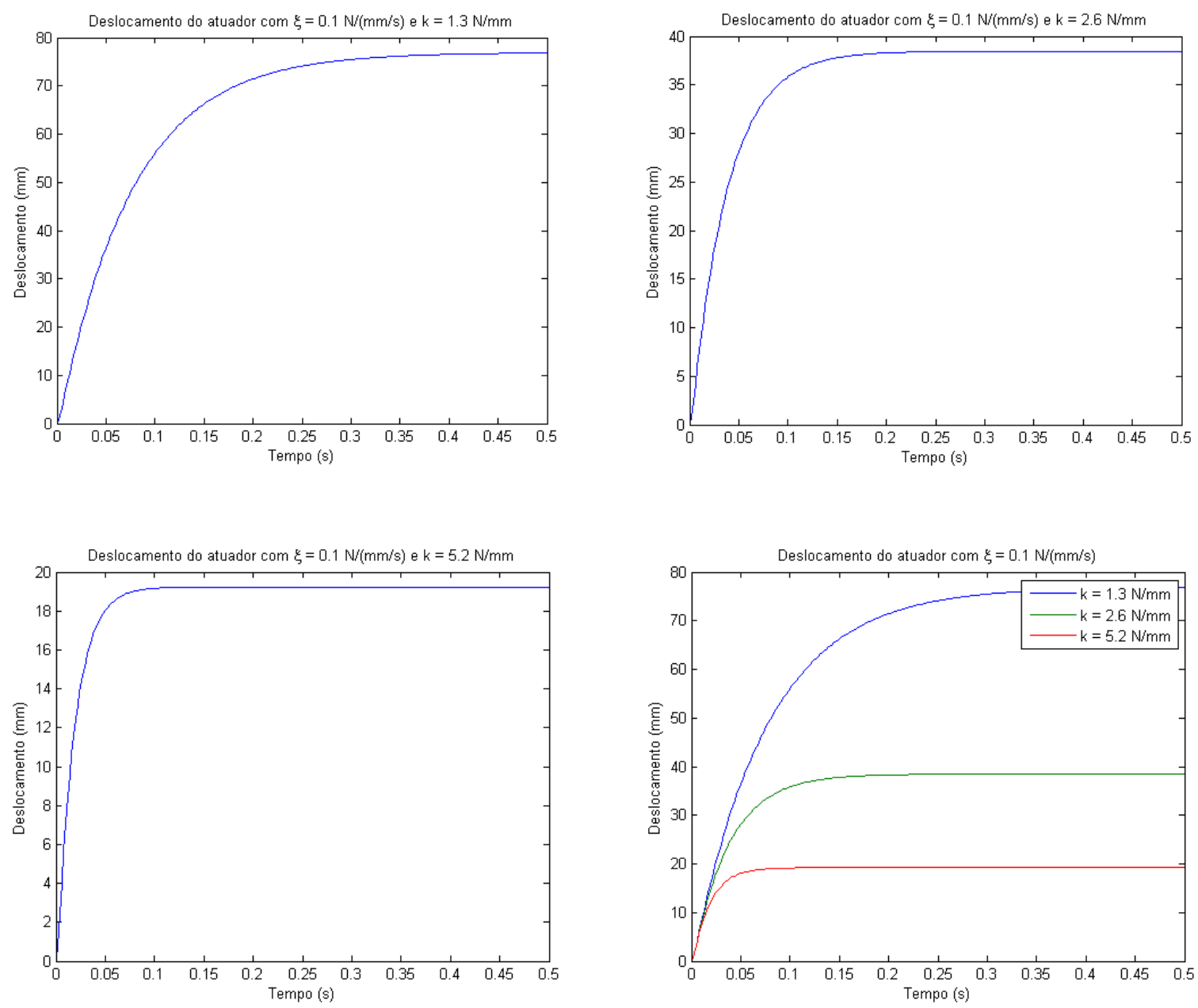

Figura 22 - Deslocamento do atuador com $\xi=0,1 \mathrm{~N} /(\mathrm{mm} / \mathrm{s})$

O sistema não oscila porém nota-se que a constante de menor rigidez, desloca-se mais semelhante ao caso $\xi=0,01 \mathrm{~N} /(\mathrm{mm} / \mathrm{s})$. 

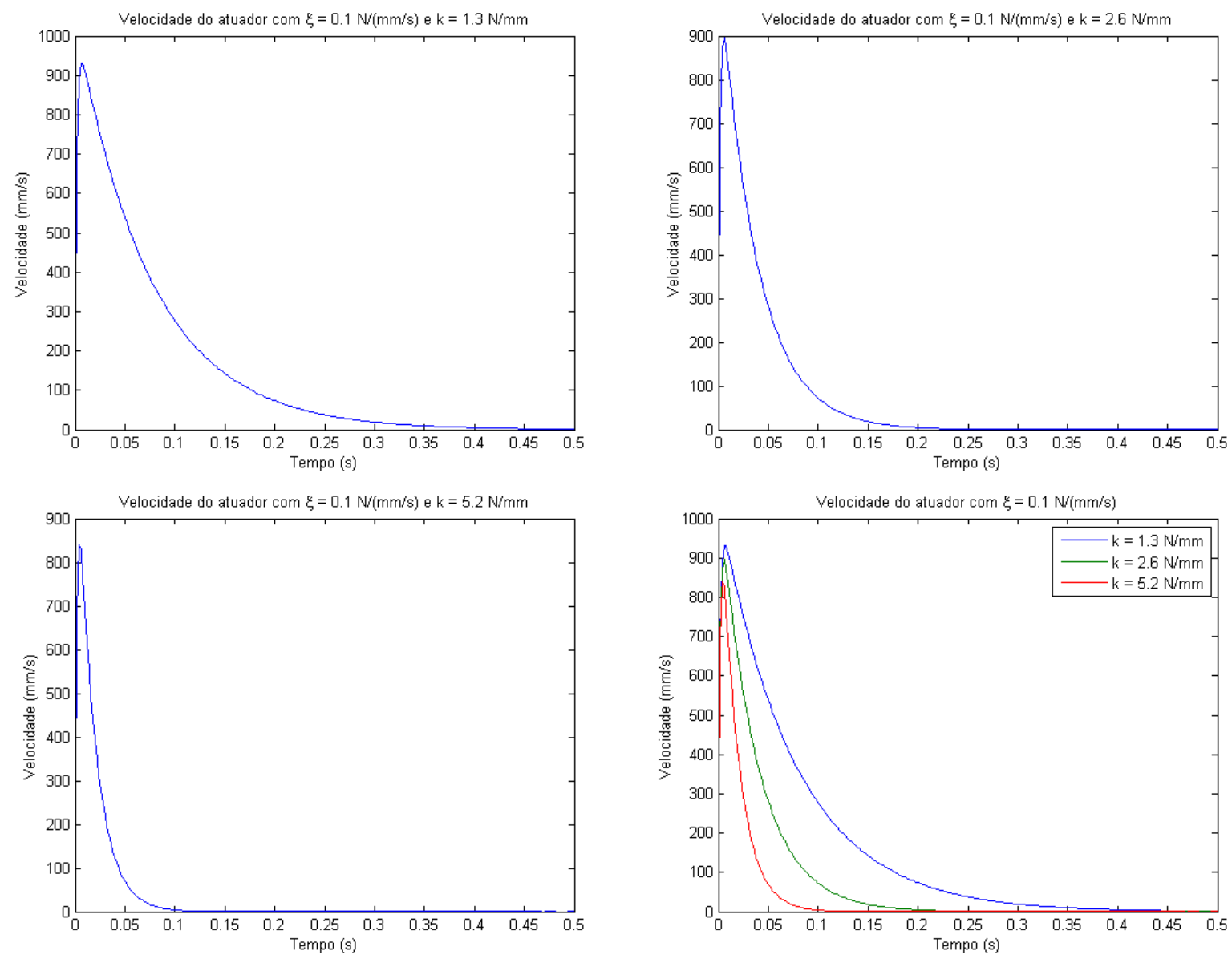

Figura 23 - Velocidade do atuador com $\xi=0,1 \mathrm{~N} /(\mathrm{mm} / \mathrm{s})$

A figura 23 indica que as três constantes de rigidez atingem sua velocidade máxima e em seguida, há um decrescimento até atingir o regime permanente. Análogo ao primeiro caso, a maior velocidade é encontrada na menor constante de rigidez. 

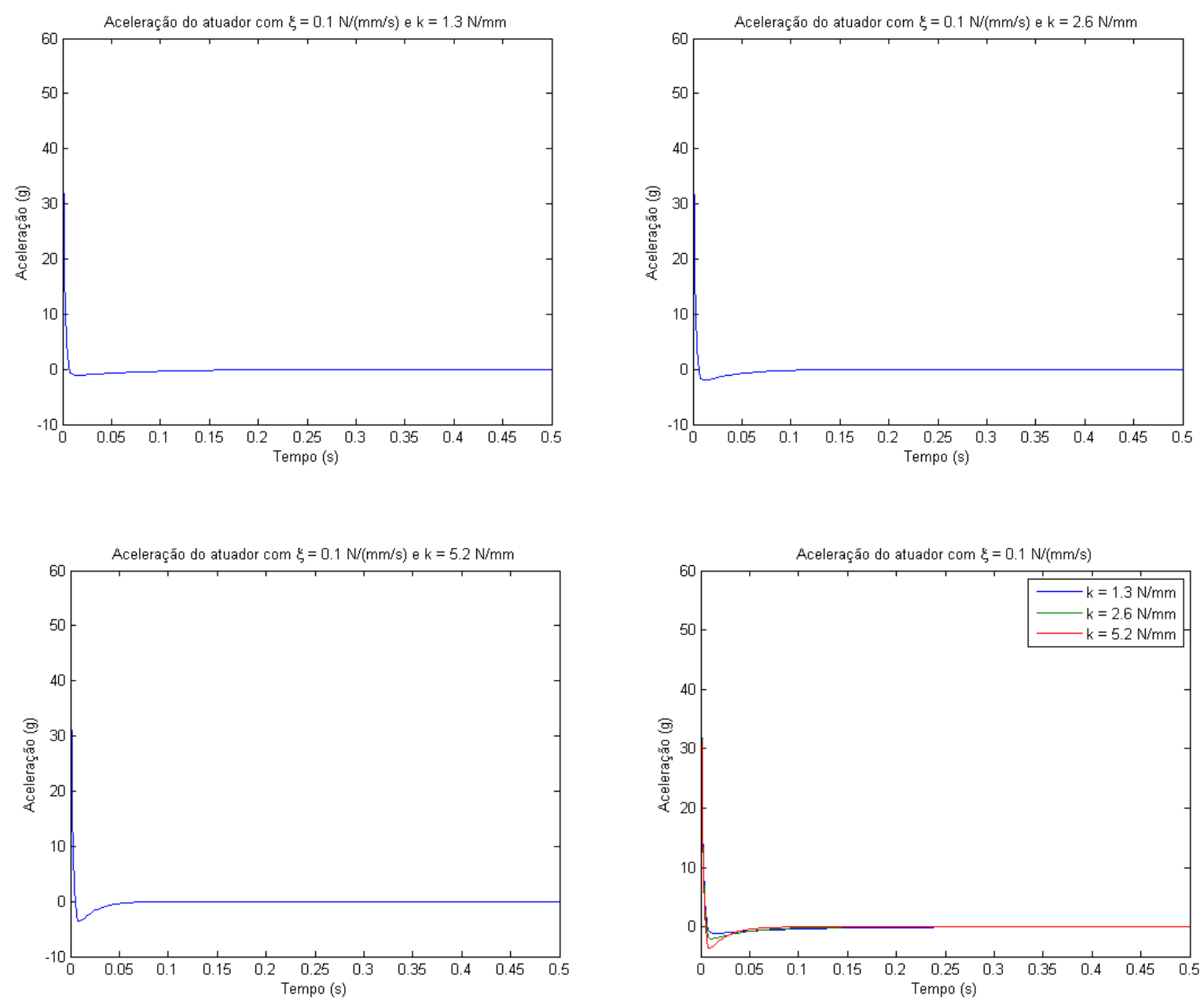

Figura 24 - Aceleração do atuador com $\xi=0,1 \mathrm{~N} /(\mathrm{mm} / \mathrm{s})$

Assim, como o gráfico de deslocamento, percebe-se a ausência de oscilação no sistema. Esta situação é denominada superamortecido.

Por último, é utilizada a constante de amortecimento para $\xi=1 \mathrm{~N} /(\mathrm{mm} / \mathrm{s})$. Os gráficos de deslocamento, velocidade e aceleração deste primeiro caso estão representados nas figuras 25 , 26 e 27 , respectivamente. 

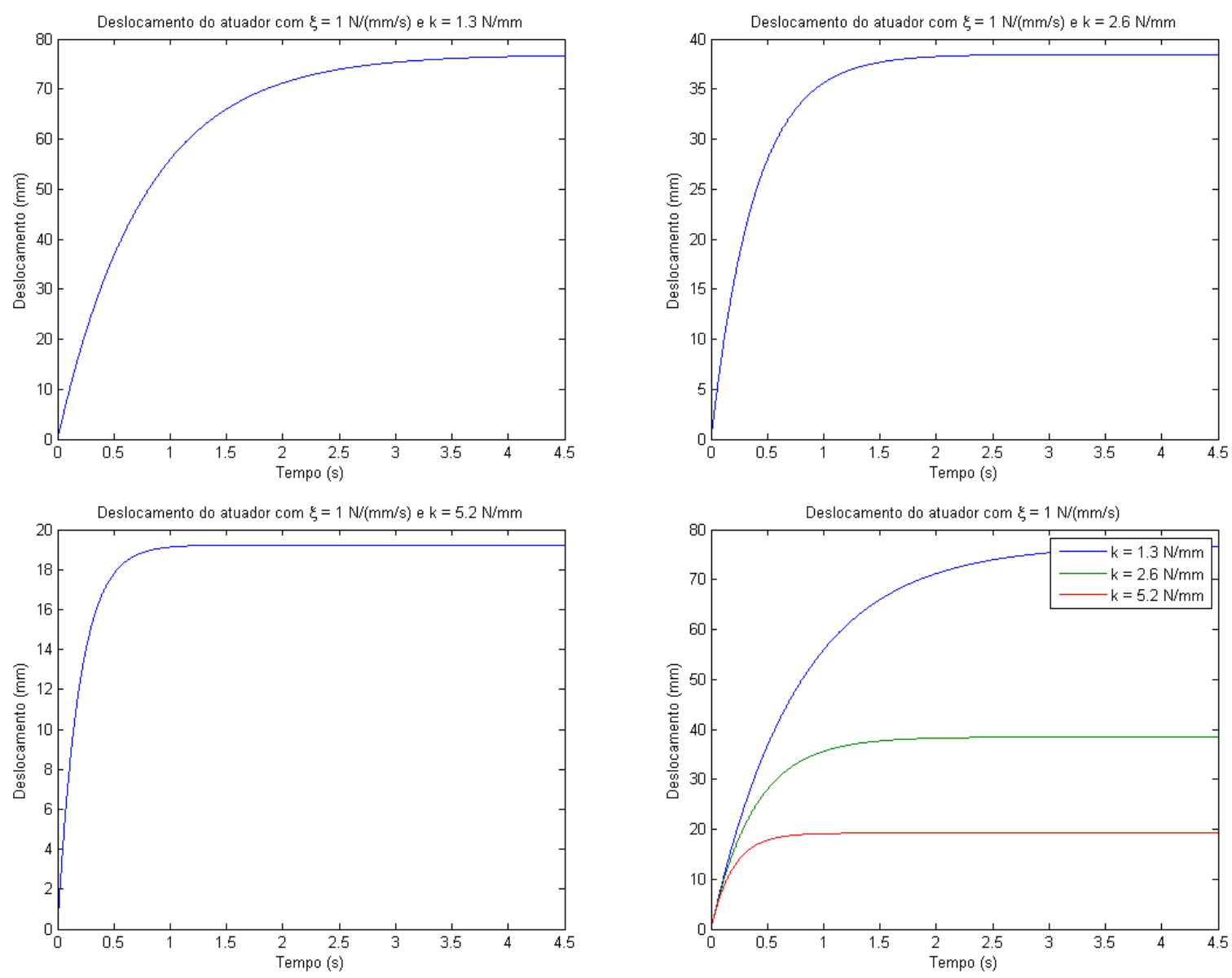

Figura 25 - Deslocamento do atuador com $\xi=1 \mathrm{~N} /(\mathrm{mm} / \mathrm{s})$

O sistema não oscila porém nota-se que a constante de menor rigidez, desloca-se mais semelhante ao caso $\xi=0,01 \mathrm{~N} /(\mathrm{mm} / \mathrm{s})$ e $\xi=0,1 \mathrm{~N} /(\mathrm{mm} / \mathrm{s})$. 

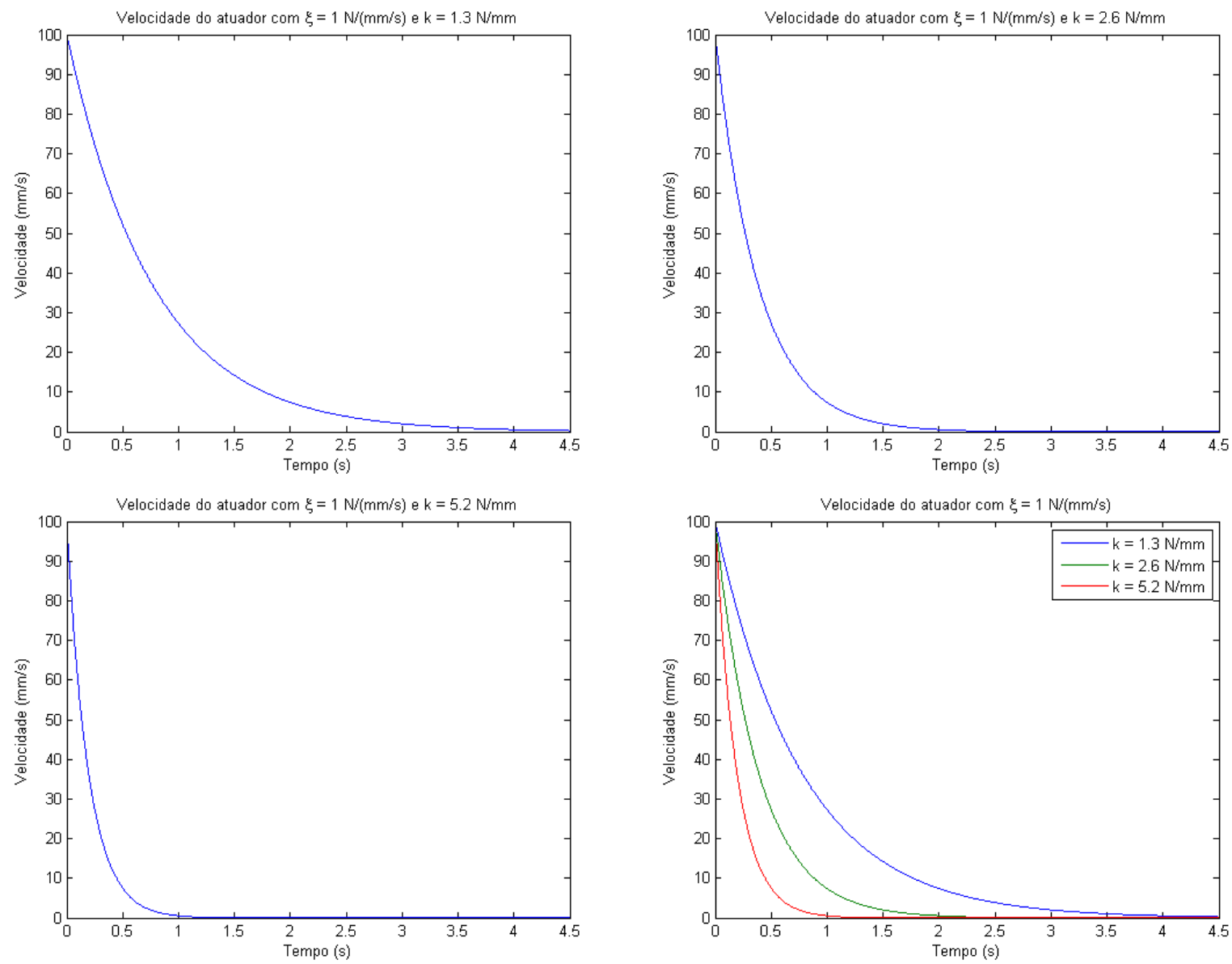

Figura 26 - Velocidade do atuador com $\xi=1 \mathrm{~N} /(\mathrm{mm} / \mathrm{s})$

As respostas no tempo representadas na figura 26 indica que todas constantes de rigidez atingem sua velocidade máxima e elas diminuem até atingir o regime permanente. Análogo aos casos anteriores, a maior velocidade é encontrada na menor constante de rigidez. 

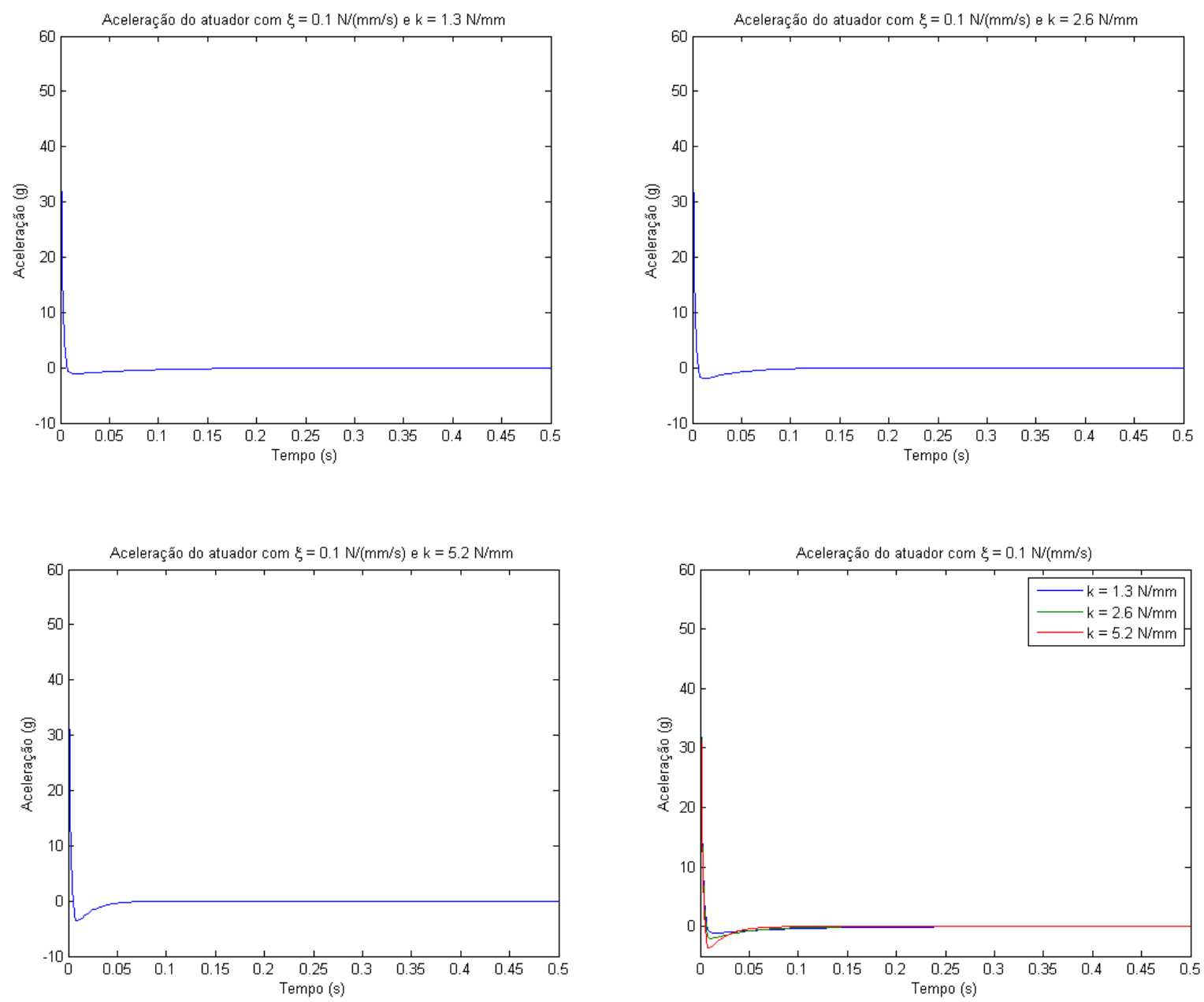

Figura 27 - Aceleração do atuador com $\xi=1 \mathrm{~N} /(\mathrm{mm} / \mathrm{s})$

Assim, como o gráfico de deslocamento, percebe-se a ausência de oscilação no sistema. Esta situação é denominada superamortecida. 


\subsubsection{Modelo detalhado}

Para estudar o comportamento do modelo detalhado, foi adicionado a curva do torque obtida pelos testes realizados com o motor elétrico. Este torque foi aplicado conforme mostra a figura 28.

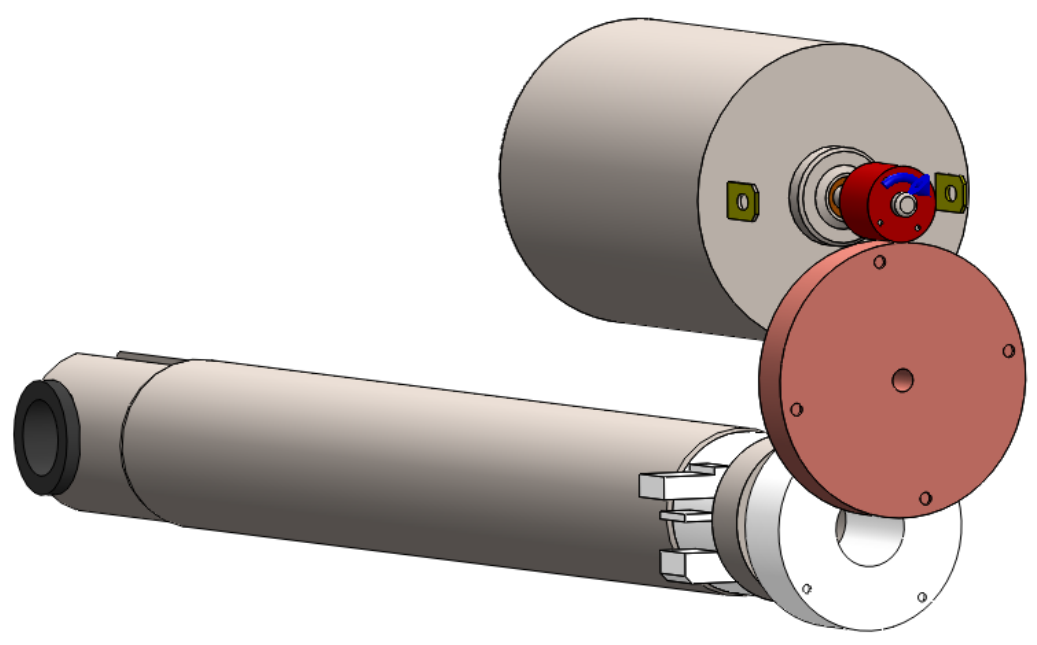

Figura 28 - Torque aplicado no modelo

As figuras 29 e 30 possuem o comportamento esperado, porém não qualitativamente. $\mathrm{O}$ atuador atinge o regime permanente em $0,2 \mathrm{~s}$ em contraste ao encontrado pelo método do Grafo de Ligação (seção 3.3). As curvas representadas pelas figuras são coerentes porque a velocidade máxima é atingida e posteriormente, decresce até a haste do atuador alcançar seu curso final. 


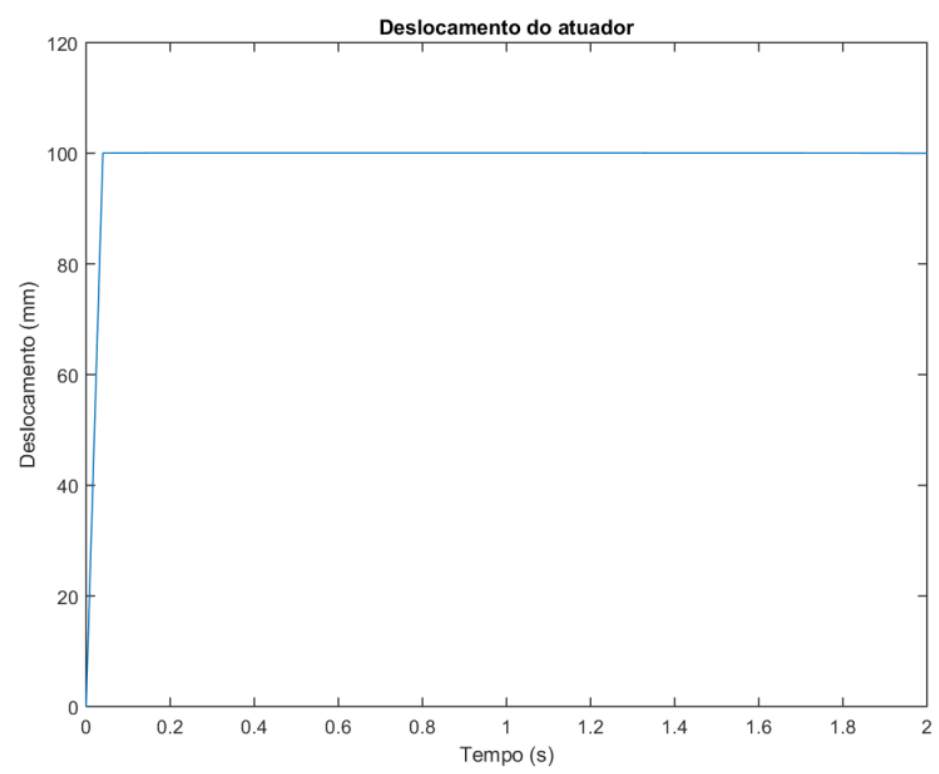

Figura 29 - Deslocamento do atuador

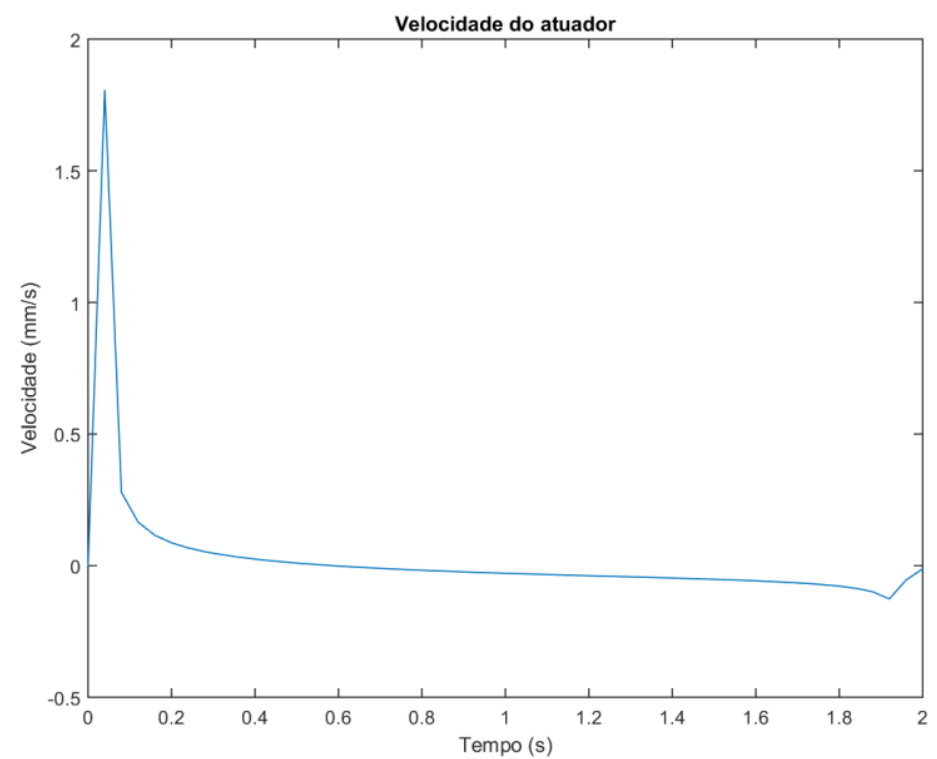

Figura 30 - Velocidade do atuador

As discrepâncias nos valores resultantes podem ser justificadas pelos elementos resistores. Eles são modelados de formas diferentes nos softwares Simulink e Solidworks. É necessária uma avaliação melhor destes parâmetros nessa ferramenta e também nos três métodos 
de interpolação, uma vez que os valores encontrados pelo Simulink estão conforme em relação aos apresentados pelo fabricante Linak.

\subsection{Simulações em MatLab/Simulink}

Nesta seção serão apresentadas as simulações obtidas por meio da técnica dos Grafos de Ligação. Para os coeficientes de dissipação $\left(R_{2}\right.$ e $\left.R_{6}\right)$, será estimado uma resistência equivalente $\left(R_{e q}\right)$ para o cálculo. O momento de inércia equivalente ao conjunto motor-engrenagem foi obtido a partir da equação 2.18. Os elementos da equação $I_{1}, I_{2}$ e $I_{3}$ foram retirados da propriedade de massa do CAD do modelo completo (seção 2.2.2).

Já o torque foi extraído dos testes realizados com o motor pelo aluno Alessandro Soares (seção 2.5). Como aproximação, a equação de segundo grau $y=0,025 x^{2}-0,1 x+0,1$ foi utilizada para o tempo entre 0 e $2 \mathrm{~s}$. Em seguida, o torque foi considerado 0 . A tabela 2 apresenta todos os valores utilizados na simulação.

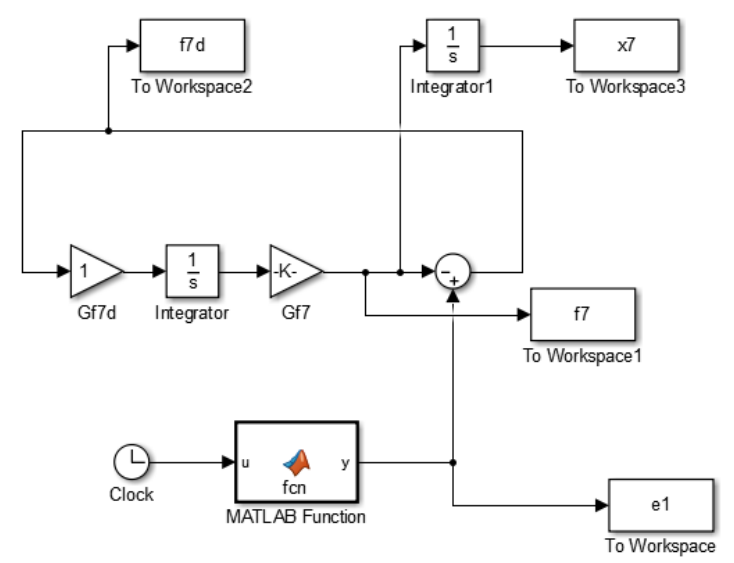

Figura 31 - Diagrama do Simulink 


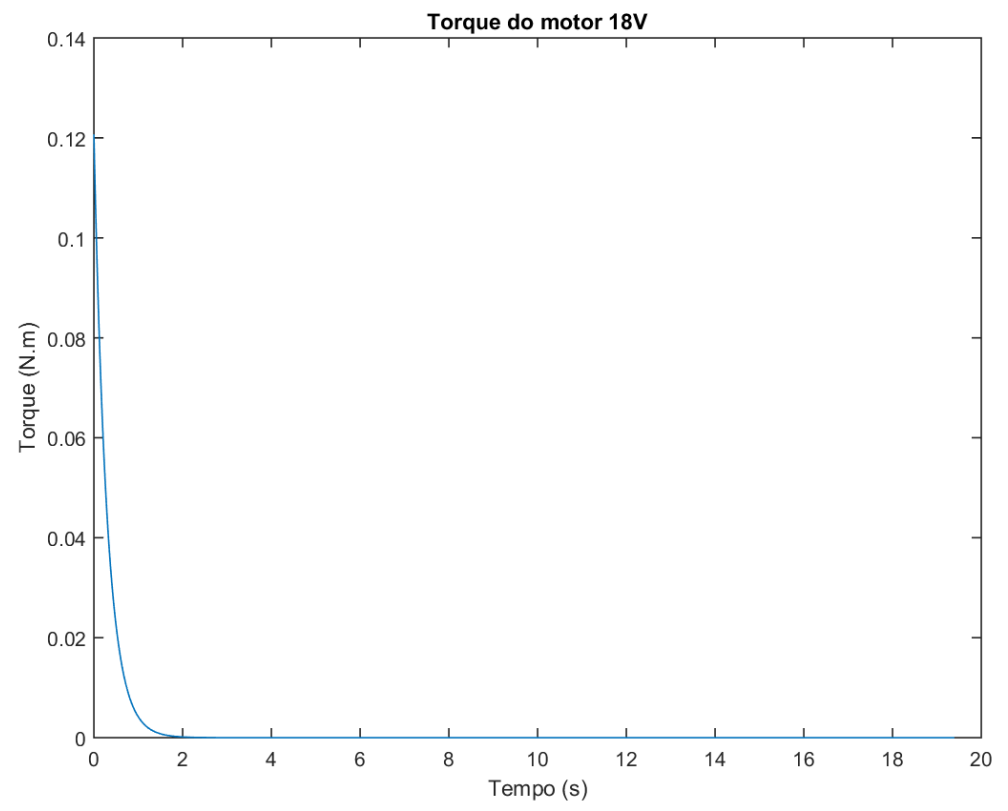

Figura 32 - Torque do motor $18 \mathrm{~V}$

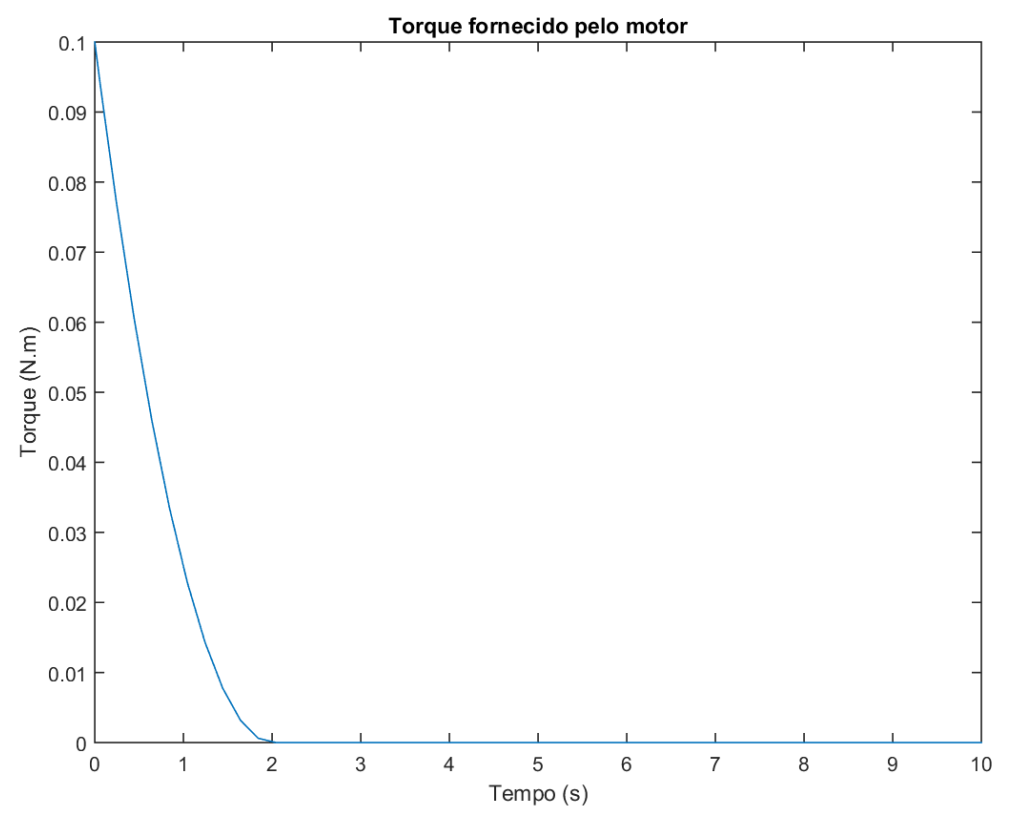

Figura 33 - Torque fornecido pelo motor 
Tabela 2 - Parâmetros utilizados

\begin{tabular}{|c|c|c|c|}
\hline Identificação & Representação & Valor & Unidade \\
\hline Momento de inércia do motor e & $I_{3}$ & 0,000056237 & $\mathrm{~kg} \cdot \mathrm{m}^{2}$ \\
conjunto de engrenagens & & 0,1749 & $\mathrm{~kg}$ \\
\hline Massa da haste & $I_{7}$ & 0,1156 & $\mathrm{~m}$ \\
\hline Razão total de transmissão & $\mathrm{m}$ & 0,0001 & $\mathrm{~N} /(\mathrm{m} / \mathrm{s})$ \\
\hline Resistência equivalente & $R_{e q}$ & 0,003 & $\mathrm{~m}$ \\
\hline Passo do parafuso & $\mathrm{p}$ & 2 & - \\
\hline Tipo de rosca & $\mathrm{Ne}$ & & \\
\hline
\end{tabular}

Com esses dados, foram obtidas as respostas no tempo para o deslocamento, a velocidade e aceleração do atuador. 


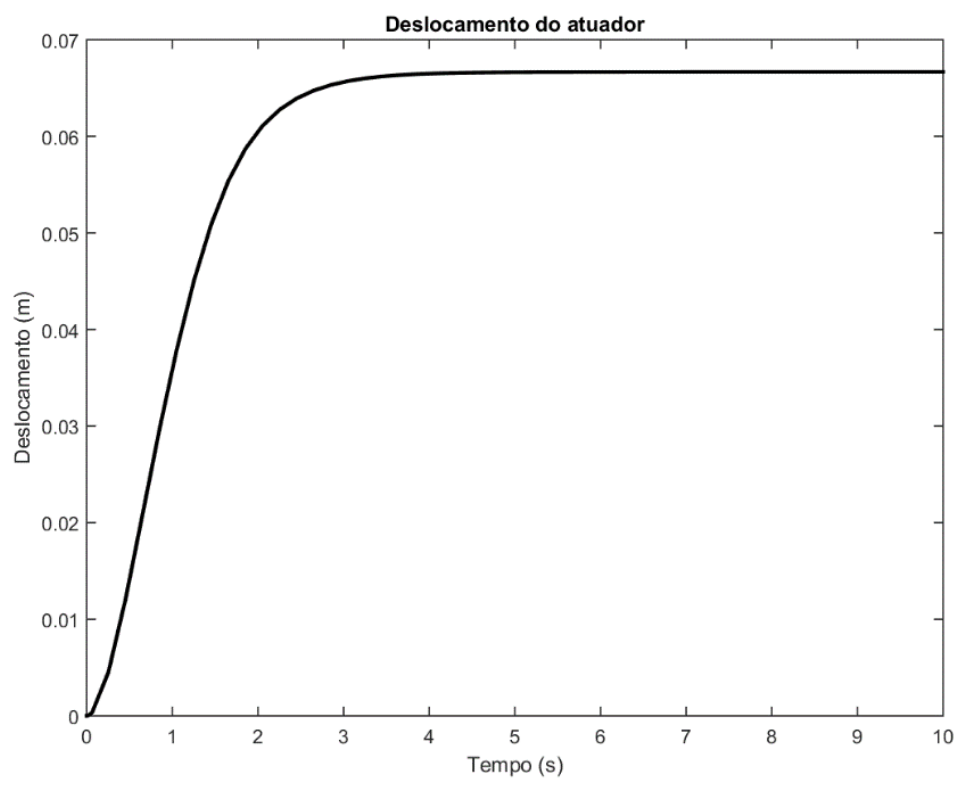

Figura 34 - Deslocamento do atuador

$\mathrm{Na}$ figura 34, nota-se que o deslocamento máximo do atuador, quando o regime permanente é atingido, é próxima de $70 \mathrm{~mm}$. De acordo com o banco de dados disponibilizado pelo fornecedor LINAK, o deslocamento máximo registrado no potenciômetro mecânico é de $100 \mathrm{~mm}$.

Se não houvesse perdas, quando o perfil de torque atingisse zero em um determinado momento (aproximadamente 2s), a aceleração também iria a zero e a velocidade permaneceria constante. Como há, a haste desacelera e a velocidade vai a zero. Por esse motivo, o atuador para antes do fim do curso máximo. 


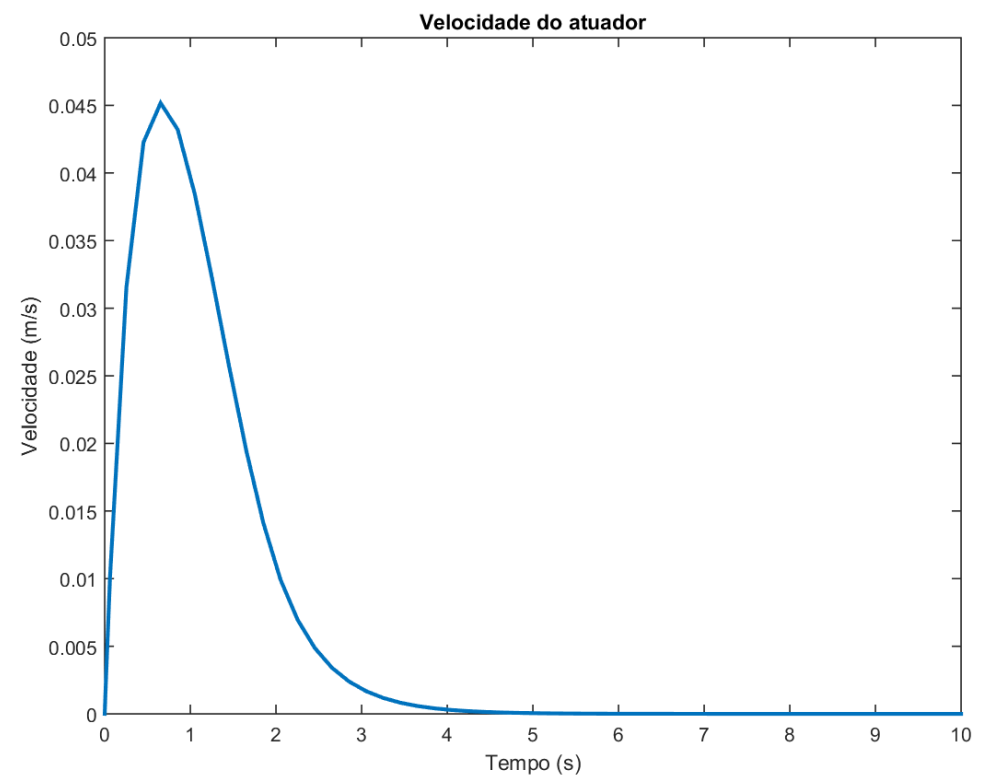

Figura 35 - Velocidade do atuador

A figura 35 representa a velocidade do atuador ao longo da simulação e sua máxima velocidade alcançada é de $45 \mathrm{~mm} / \mathrm{s}$. O valor encontrado é bastante coerente pois de acordo com o fabricante, a velocidade máxima é de $40 \mathrm{~mm} / \mathrm{s}$.

A curva da simulação também está adequada porque a velocidade atinge seu máximo e em seguida, decresce até a haste do atuador alcançar seu curso final. Nota-se também que quando a velocidade se estabiliza em zero, a haste está parada na posição final. 


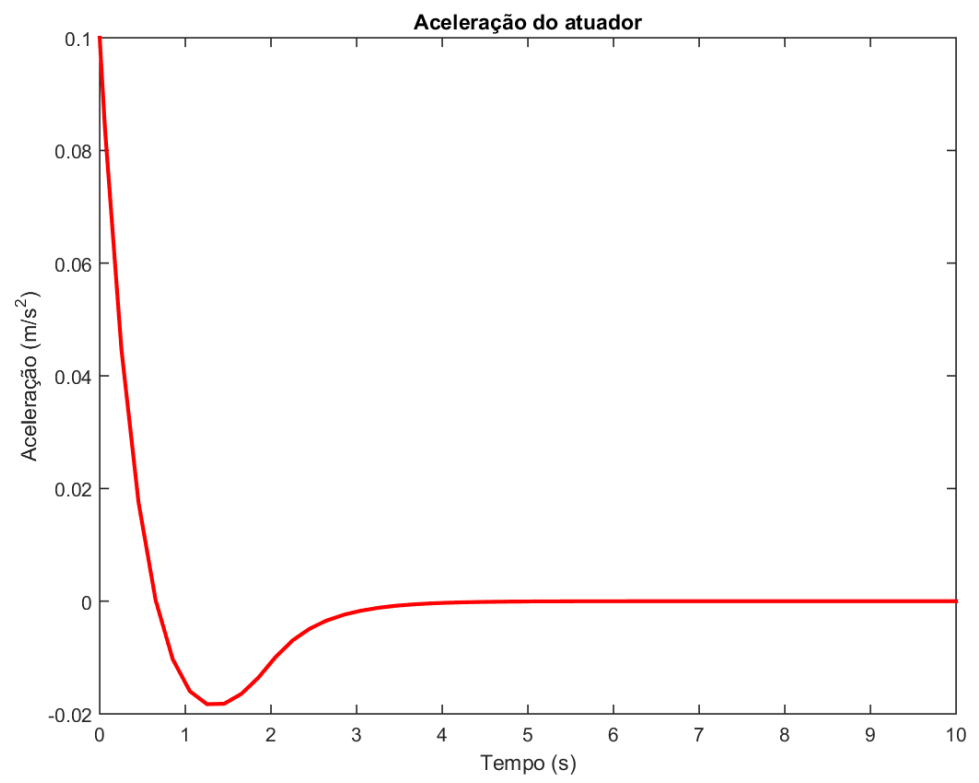

Figura 36 - Aceleração do atuador

A figura 36 indica a resposta no tempo da aceleração do atuador. Para iniciar o movimento da haste, sua aceleração é máxima. Observa-se que no tempo de aproximadamente 1,5s, a aceleração é negativa para frear a haste e ser possível atingir seu curso final. É possível notar também que há um decrescimento da aceleração conforme o torque diminuiu ao longo do tempo. 


\section{Conclusões e etapas futuras}

\subsection{Conclusões}

A técnica de Grafos de Ligação é bastante apta para modelar os elementos de um sistema onde há fluxo de potência (esforço e fluxo). A simulação deste sistema por meio do SIMULINK/MATLAB comprovou a simplicidade e facilidade no emprego desta metodologia.

A ferramenta Solidworks contribuiu para fornecer dados do modelo de inércia do modelo detalhado do atuador. Com isso, foi possível realizar as simulações e compreender o comportamento do atuador em questão.

\subsection{Etapas futuras}

Este trabalho se baseou principalmente na técnica dos Grafos de Ligações. O procedimento como está formalizado neste trabalho pode ser utilizado como referência para compreensão desta metodologia.

Com base na fundamentação teórica desenvolvida e nos resultados obtidos, propõe-se como sugestões: sofisticação do procedimento; análise do sistema elétrico do atuador e este último sendo acoplado em algum outro mecanismo, por meio da técnica dos Grafos de Ligação; realização de testes experimentais com o atuador para ser melhorar a estimativa do coeficiente de dissipação; inclusão de um esquema de controle baseado no modelo. 


\section{Referências}

1 - SPERANZA NETO, MAURO. DA SILVA, FERNANDO RIBEIRO. Modelagem e análise de sistemas dinâmicos. Pontifícia Universidade Católica do Rio de Janeiro. Julho, 2005.

2 - COESTER. http://www.coester.com.br/, acessado em 29 de maio de 2016.

3 - LINAK. http://www.linak.com.br/, acessado em 29 de maio de 2016.

4 - MESQUITA, ANDRÉ CESTARI DE. Desenvolvimento de um atuador linear elétrico para veículo de competição. Universidade de São Paulo, São Carlos, 2009.

5 - JULIANI, ALINE. Projeto e Construção de um Motor Elétrico Linear Aplicado à Bioengenharia. Universidade de São Paulo, São Carlos, 2011.

6 - MARTINS, ADAIR. O uso da técnica dos grafos de ligação para a simulação de centrais hidrelétricas em regime transitório. Universidade Federal de Itajubá, Minas Gerais, 2004.

7 - NOGUEIRA, ALLAN. Dynamic models of parallel mechanisms using power flow approach. Congresso Nacional de Engenharia Mecânica, Fortaleza, 2016.

8 - MANIPULADORES. http://paginas.fe.up.pt/ aml/man para.htm, acessado em 8 de junho de 2016.

9 - SOLIDWORKS $\quad$ MOTION $\quad-\quad$ IST $\quad$ SISTEMAS.

http://istsistemas.com.br/solidworks-motion/, acessado em 9 de junho de 2016.

10 - SQÉDIO http://www.sqedio.com, acessado em 9 de junho de 2016>.

11 - MOTTA, ANDRÉ. NUNES, DIOGO. Projeto modular da suspensão de um veículo terrestre. Instituto Militar de Engenharia, Rio de Janeiro, 2008. 
n\%E2micos/04 Elem Sist Mec.pdf, acessado em: 18 de junho de 2016.

13 - IME. http://aquarius.ime.eb.br/ moniz/pdf/matr01.pdf, acessado em 18 de junho de 2016.

14 - $\quad$ IME-USP.

http://www.ime.usp.br/ oda/contents/01Matem\%E1tica/01Sistemas\%20Din\%E2 micos/15_An_Resp_Livre_Sist_2_Ordem.pdf, acessado em 19 de junho de 2016.

15 - DP ALABARCE. http://dpaautomacao.com.br/, acessado em 19 de junho de 2016.

16 - VITORINO, CÁSSIA. Modelagem dinâmica de caixa multiplicadora de velocidades de aerogeradores. Universidade de Brasília, Brasília, 2012.

17 - MOREIRA, ALESSANDRO F. Princípios elementares de mecânica. Dinâmica do acionamento mecânico. Perdas.

18 - AKIMA, H. A New Method of Interpolation and Smooth Curve Fitting Based on Local Procedures. J.ACM, vol. 17, no. 4, pp. 589-602. Boulder, EUA, Outubro de 1970.

19 - DASSAULT SYSTÈMES SOLIDWORKS CORP. Understanding

Motion Simulation. 2008.

20 - NIZAR, M. H. M. SolidWorks Motion Study Tutorial. South Dakota School of Mines \& Technology. Dakota do Sul, EUA, Agosto, 2013. 


\section{Apêndice}

Desenho técnico do atuador elétrico linear

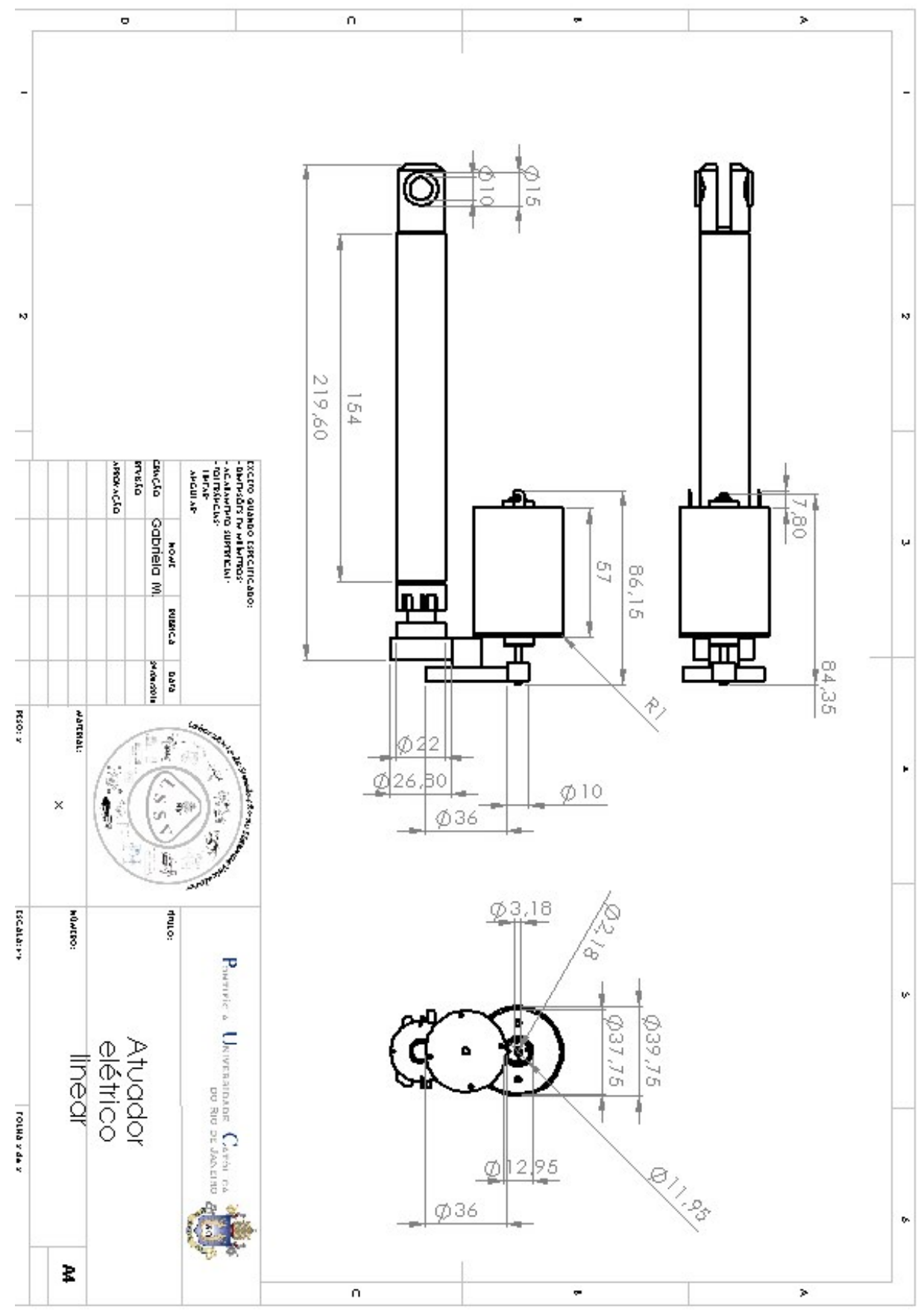




\section{Componentes do modelo detalhado}

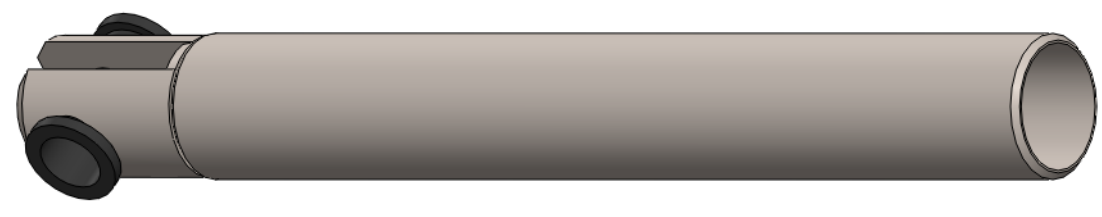

Figura 37 - Haste completa

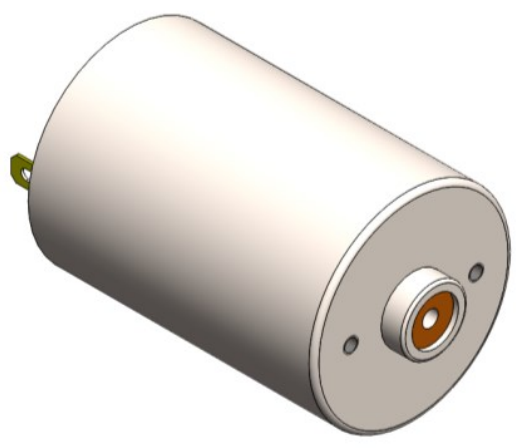

Figura 38 - Motor elétrico

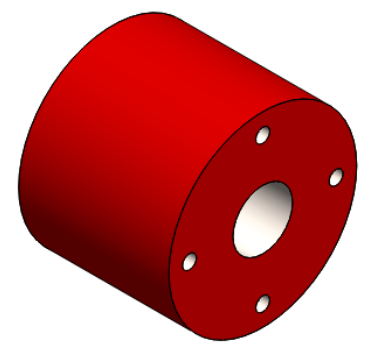

Figura 39 - Engrenagem A 


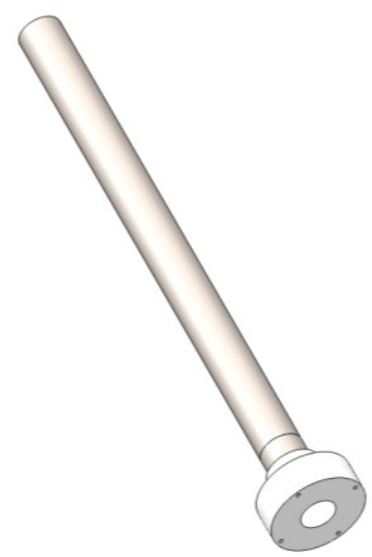

Figura 40 - Conjunto parafuso-rolamento-engrenagem $C$

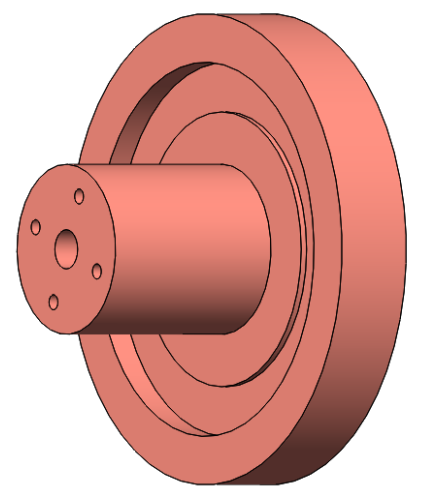

Figura 41 - Engrenagem B

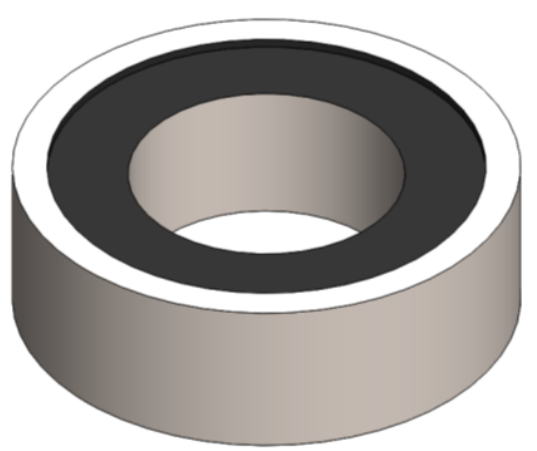

Figura 42 - Rolamento da haste 


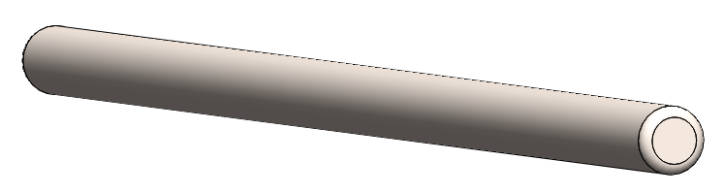

Figura 43 - Eixo do motor

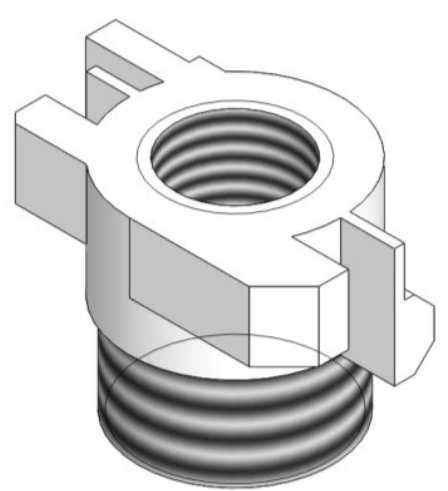

Figura 44 - Acoplamento da haste 
Datasheet do atuador Linak LA12

Nessa seção estão presentes algumas páginas do datasheet. O completo está localizado no CD Anexo.

PRODUCT DATA SHEET

Actuator LA12

Thanks to its small size and outstanding performance the actuator LA12 prowides a practical and cost-effective alternative to small-scale traditional hydraulic and pneumatic systerns. The LA12 is ideal for applications requiring short linear movernents. After many years on the

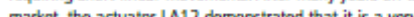
reliable and robust actuator that can handle almost any situation and challenge.

Features:

- 12 or 24 V DC permanent magnetic motor

- Max. thrust $750 \mathrm{~N}$

- Max. speed up to $40 \mathrm{~mm} / \mathrm{sec}$ depending on load and

spindle pitco

- Stroke length trom 19 to $130 \mathrm{~mm}$

- Compact design, built-in dimensions $245 \mathrm{~mm}$

(up to $355 \mathrm{~mm}$ )

- Piston rod and back fixture in high-strength plastic

- Protection

- Built-in endstop switches

Options in general:

- Stainless steel inner tubes, piston rod eyes and back

faxtures

- Protection class: IP6E

- Reed switch

- IC options including:

- IC - Integrated Controller

- Hall sensor

- Analogue or digital feedback for precise positioning - Mechanical potentiometer (max. $100 \mathrm{~mm}$ stroke length)

- Endstop signals

- Ready signal for diagnostics

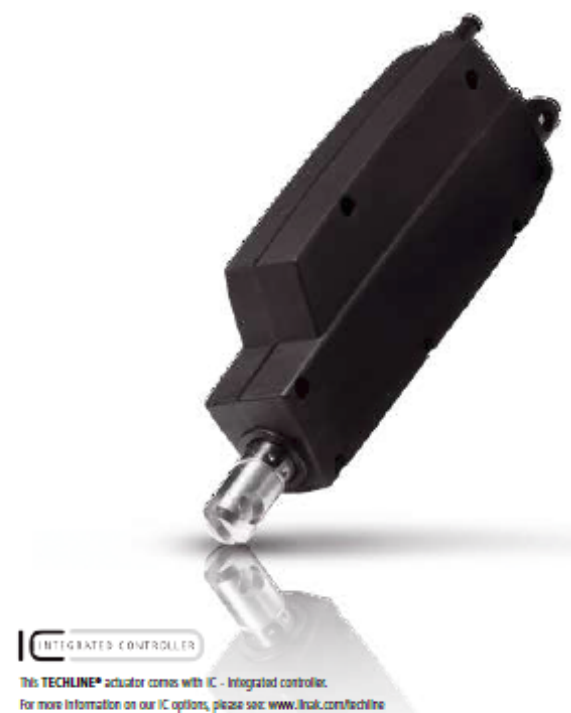

- Usage: Duty cycle at $300 \mathrm{~N}$ and $4 \mathrm{~mm}$ pitch is max. $40 \%$ Duty ocle at $200 \mathrm{~N}$ and $6 \mathrm{~mm}$ pitch is max. $60 \%$ Duty cycle at $200 \mathrm{~N}$ and $6 \mathrm{~mm}$ pitch is max. $60 \%$ ambient temperature of $+5^{\circ} \mathrm{C}$ to $+40^{\circ} \mathrm{C}$

- Ambient operating temperature: $-20^{\circ}$ to $+60^{\circ} \mathrm{C}$, full performance from $+5^{\circ} \mathrm{C}$ to $+40^{\circ} \mathrm{C}$ 
Technical specifications

\begin{tabular}{|c|c|c|c|c|c|c|c|c|c|c|c|c|}
\hline \multirow[t]{2}{*}{ Type } & \multirow{2}{*}{$\begin{array}{c}\text { Motor } \\
\text { voltage } \\
\text { (V) }\end{array}$} & \multirow{2}{*}{$\begin{array}{l}\text { Spindle } \\
\text { Pitch } \\
(\mathrm{mm})\end{array}$} & \multirow{2}{*}{$\begin{array}{c}\text { Thrust } \\
\text { max. } \\
\text { Push/Pull } \\
\text { (N) }\end{array}$} & \multirow{2}{*}{$\begin{array}{l}\text { Self-lock } \\
\text { max. } \\
\text { (Push) } \\
\text { (N) }\end{array}$} & \multirow{2}{*}{$\begin{array}{c}\text { Self-lock } \\
\text { max. } \\
\text { (Pull) } \\
\text { (N) }\end{array}$} & \multicolumn{2}{|c|}{$\begin{array}{c}\text { "Typical speed } \\
(\mathrm{mm} / \mathrm{s})\end{array}$} & \multicolumn{3}{|c|}{$\begin{array}{c}\text { Stroke length } \\
\text { (in steps of } 30 \mathrm{~mm} \text { ) }\end{array}$} & \multicolumn{2}{|c|}{$\begin{array}{l}\text { "Typical Amp. } \\
\text { (A) }\end{array}$} \\
\hline & & & & & & $\begin{array}{c}\text { No } \\
\text { load }\end{array}$ & $\begin{array}{l}\text { Full } \\
\text { load }\end{array}$ & Min. & & Max. & $\begin{array}{c}\text { No } \\
\text { load }\end{array}$ & $\begin{array}{l}\text { Full } \\
\text { load }\end{array}$ \\
\hline $12 \times \times 00-1 \times \times X \times 12 \times X$ & 12 & 2 & 750 & 750 & 375 & 14 & 5 & 40 & - & 130 & 1.75 & 4.6 \\
\hline $12 \times \times 00-1 \times X \times 24 \times X X$ & 24 & 2 & 750 & 750 & 375 & 14 & 6 & 40 & - & 130 & 0.75 & 2.2 \\
\hline $12 \times \times 00-2 \times \times X \times 12 \times X$ & 12 & 4 & 300 & 300 & 150 & 27 & 16 & 40 & - & 130 & 1.75 & 2.5 \\
\hline $12 \times \times 00-2 \times X \times 24 \times X X$ & 24 & 4 & 300 & 300 & 150 & 27 & 16 & 40 & - & 130 & 0.75 & 1.5 \\
\hline $12 \times \times 000-3 \times \times \times \times 12 \times X$ & 12 & 6 & 200 & 200 & 100 & 40 & 28 & 40 & - & 130 & 1.75 & 2.2 \\
\hline $12 \times \times X 00-3 \times X \times 24 \times 2 X$ & 24 & 6 & 200 & 200 & 100 & 40 & 28 & 40 & - & 130 & 0.75 & 1.0 \\
\hline
\end{tabular}

- The typical values can have a variation of $\pm 20 \%$ on the current values and $\pm 10 \%$ on the speed values.

Neasurements are made with an actuator in connection with a stable power supply and an ambient temperature at $20^{\circ} \mathrm{C}$

\footnotetext{
- Self locking ability

To ensure maximum self-locking ability, please be sure that the motor is shorted when stopped. Actuators with integrated controller provide this feature, as lang as the actuator is powered.

- When using soft stop on a DC-motor, a short peak of higher voltage will be sent back towards the power supply. It is important when selecting the power supply that it does not turn off the output, when this backwards load dump occurs.
}

Stroke and built-in tolerances

\begin{tabular}{|c|c|c|c|c|c|}
\hline Platform options & Descriptions & Stroke tolerance & Example for $100 \mathrm{~mm}$ stroke & BID tolerance & Example for $245 \mathrm{~mm}$ BID \\
\hline $12 X 00000 X X X X X X X X$ & All variants & $+2 /-2 \mathrm{~mm}$ & 98 to $102 \mathrm{~mm}$ & $+2 /-2 \mathrm{~mm}$ & 243 to $247 \mathrm{~mm}$ \\
\hline
\end{tabular}


Desenhos técnicos dos elementos de acoplamento dos rolamentos nos atuadores

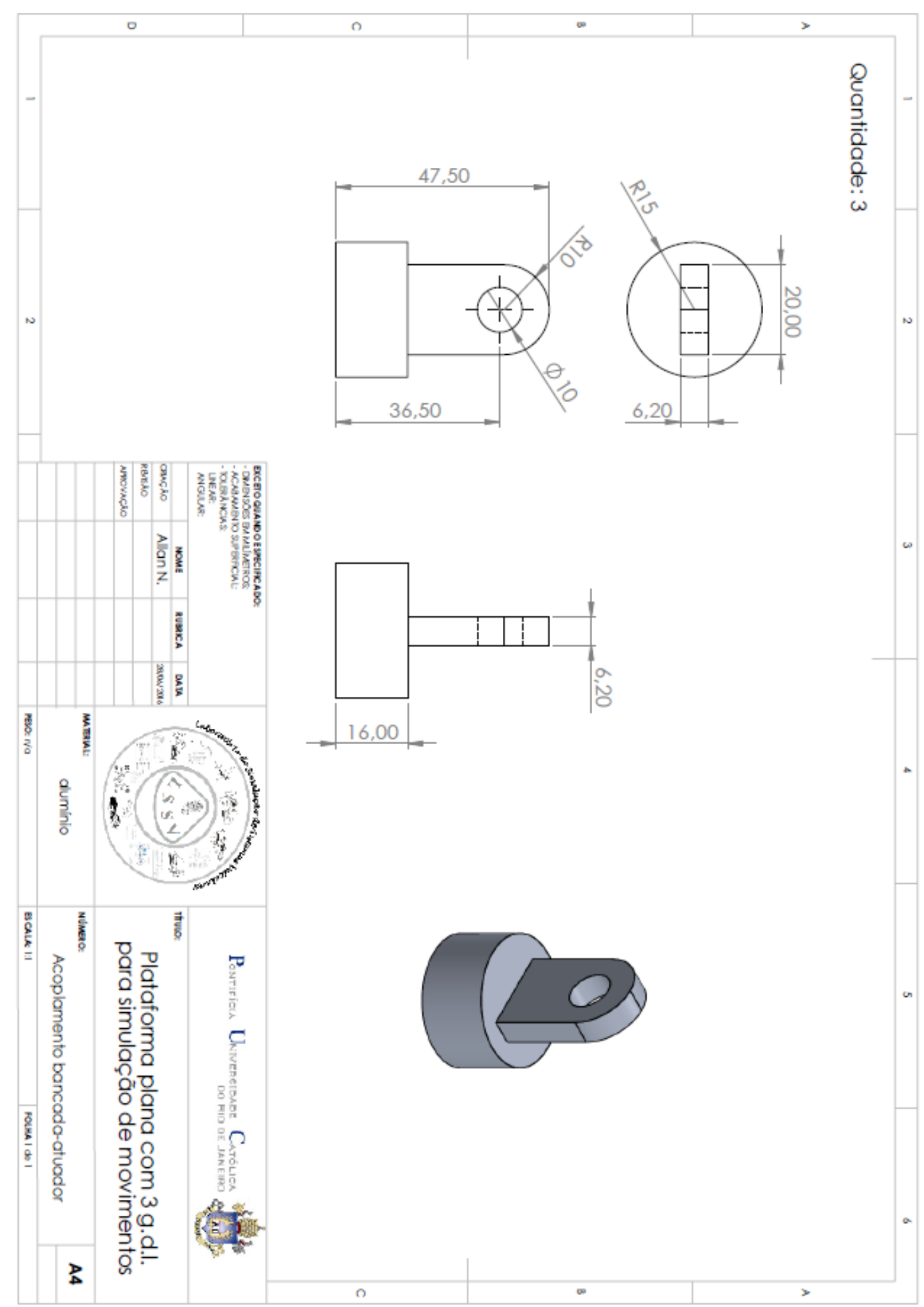




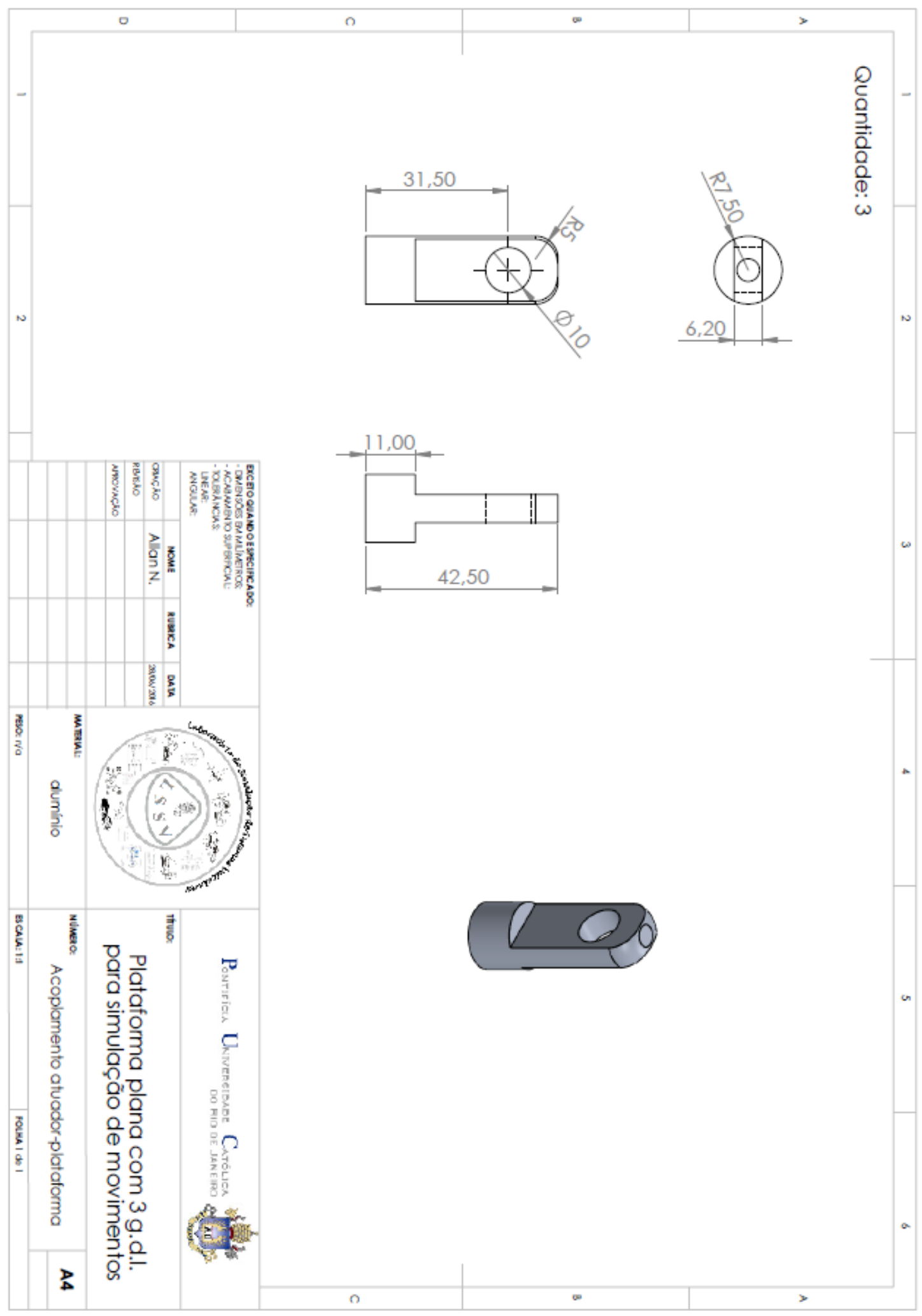




\section{Fotos da simulação utilizando o programa SprutCAM}

As imagens abaixo representam a operação de fresagem usando o programa SprutCam. Uma delas é o acoplamento da bancada com o rolamento da base da plataforma e outra é uma das seis partes que compõem a plataforma móvel.

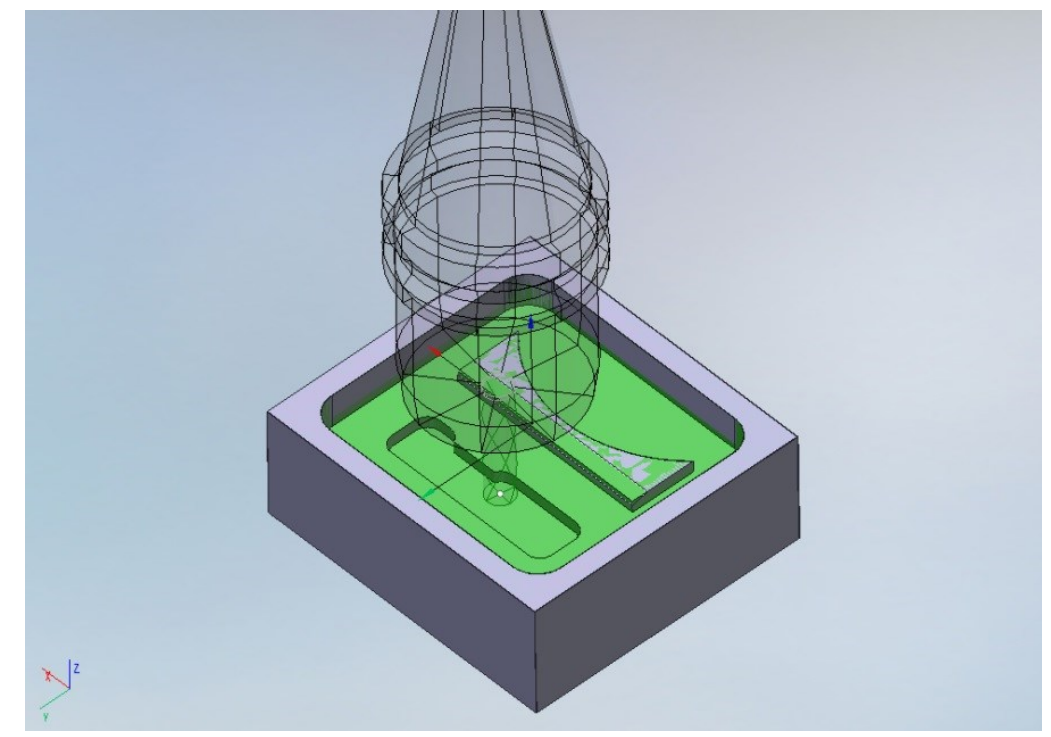

Figura 45 - Peça em operação

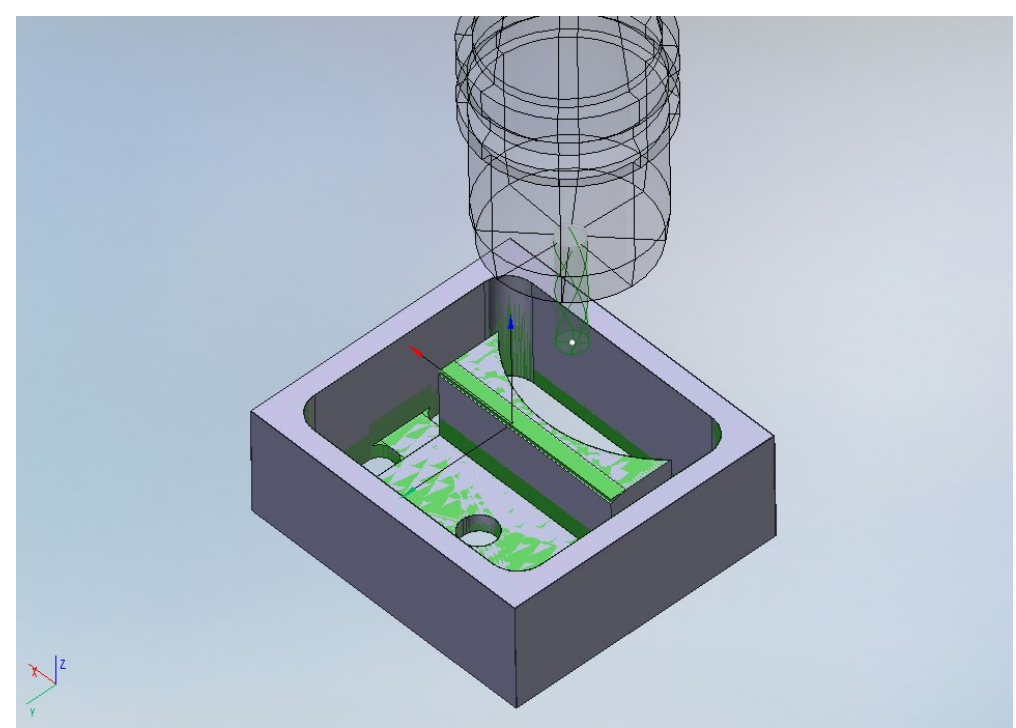

Figura 46 - Peça finalizada 


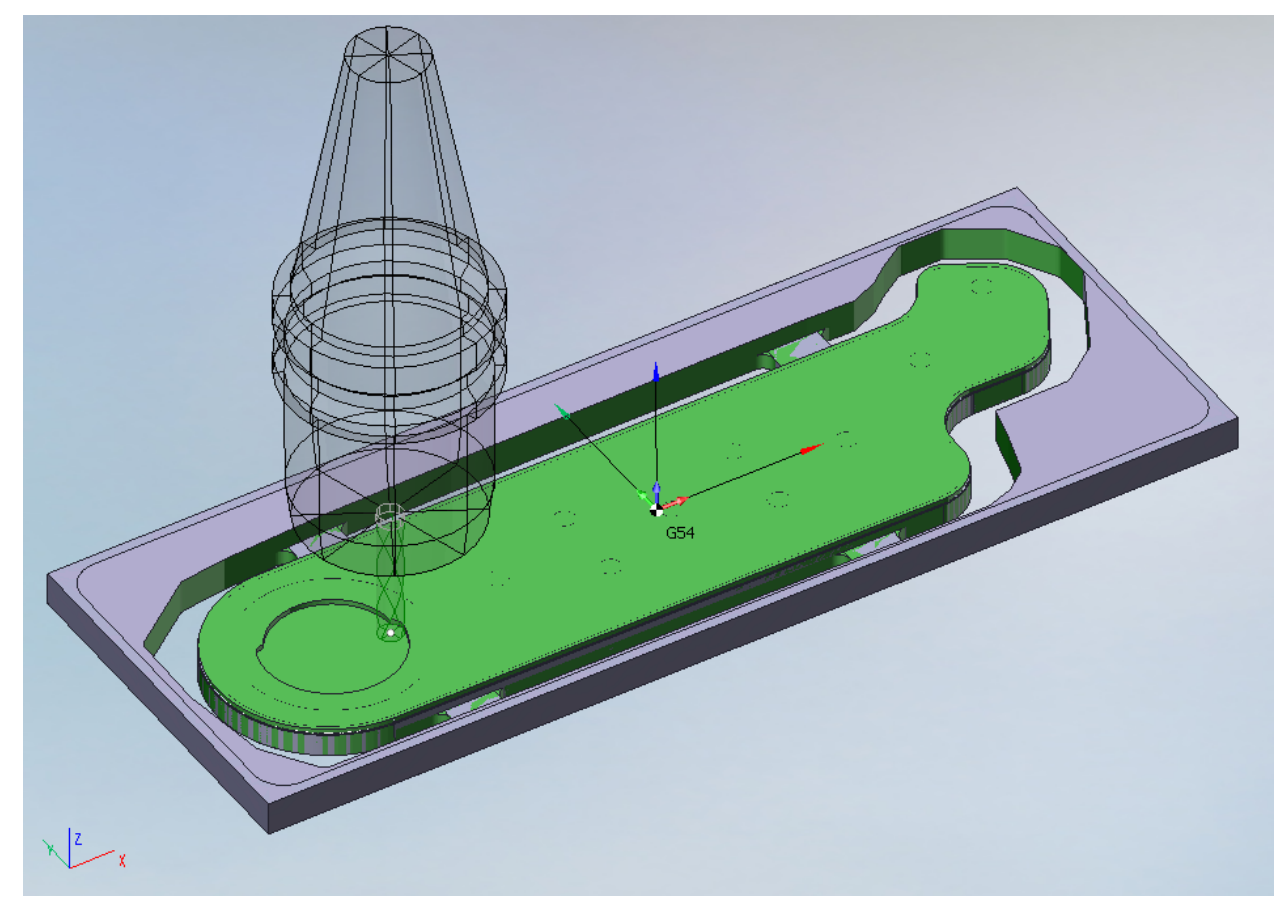

Figura 47 - Peça em operação

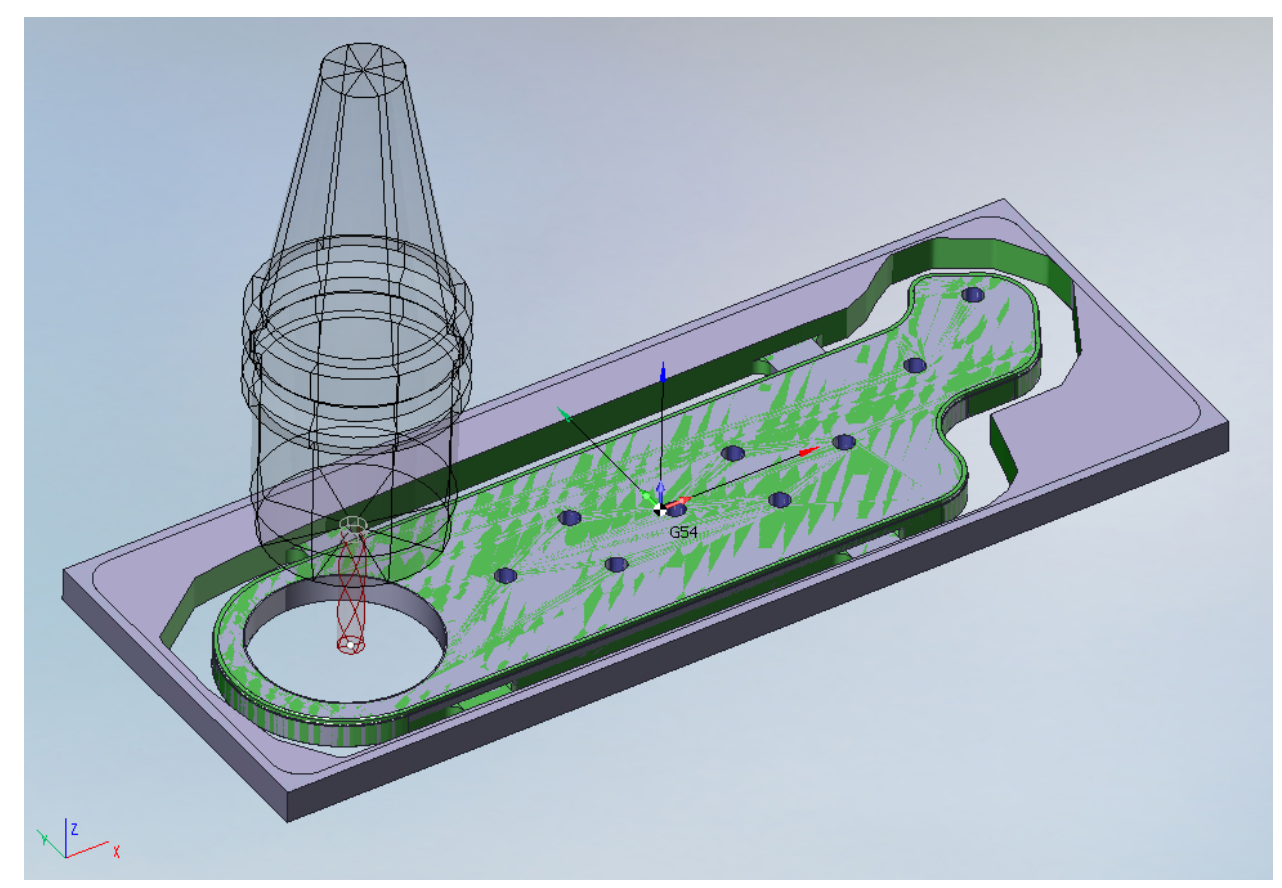

Figura 48 - Peça finalizada 


\section{ANEXO}

1. Atuador elétrico linear simplificado

2. Atuador elétrico linear detalhado

2.1. Gráficos

2.2. Animação realizada pelo Solidworks

3. Arquivos Matlab/Simulink

4. Datasheet do atuador Linak LA12

5. Curvas características do motor

6. Imagens da bancada e plataforma plana do Allan 